جامعتمالموصل

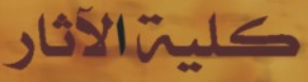

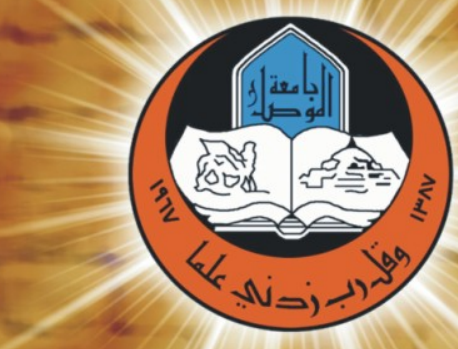

$$
\begin{aligned}
& \text { وزارة التعليمالعالي } \\
& \text { والبحث العلمي }
\end{aligned}
$$

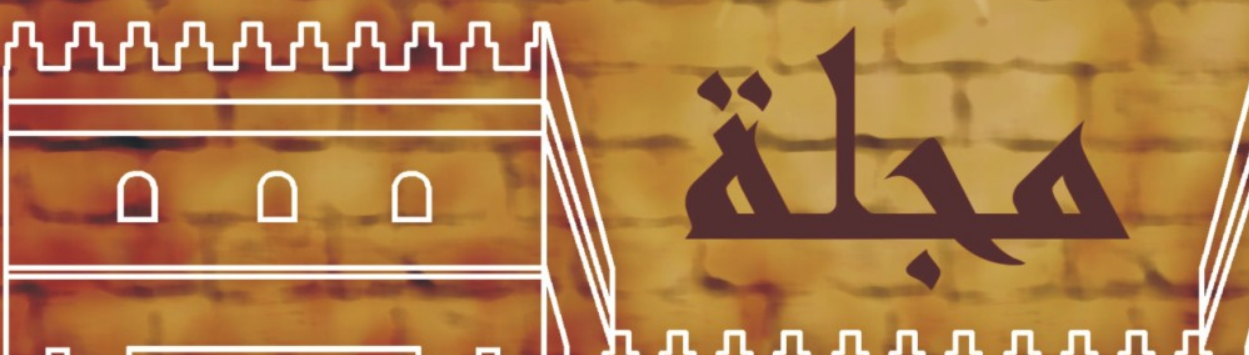

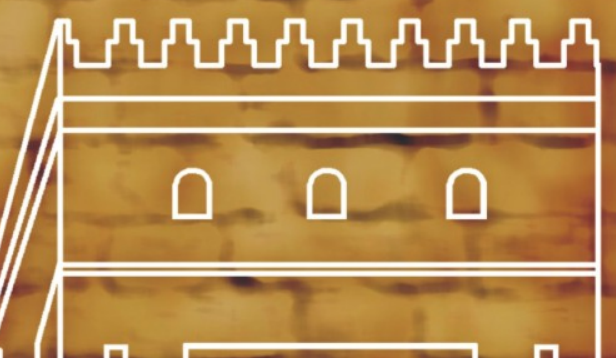

(3)

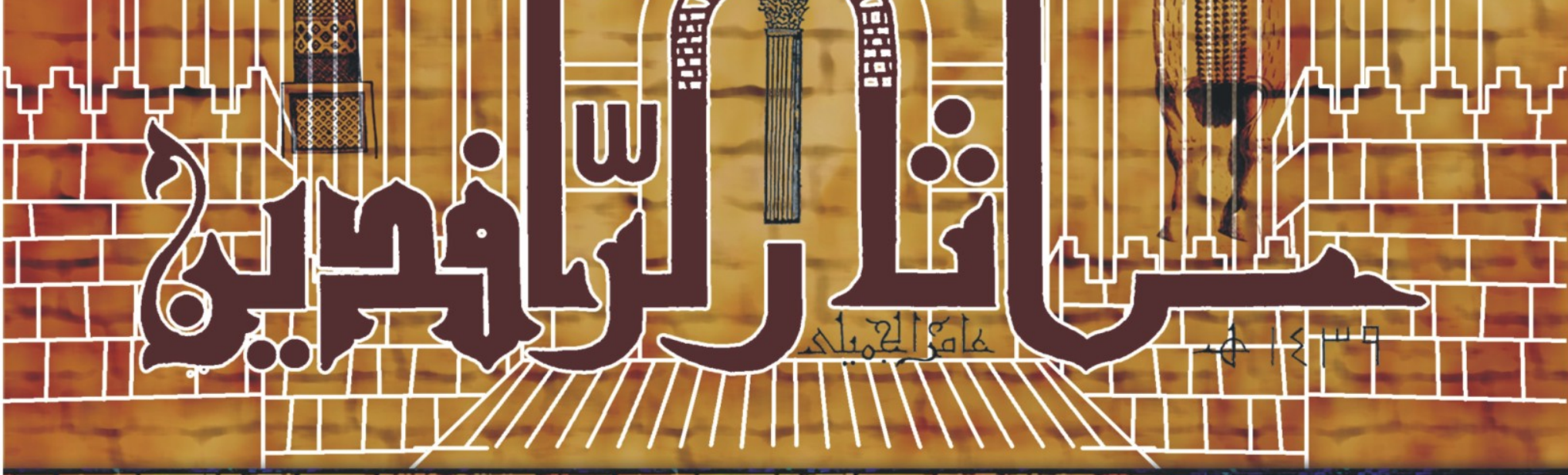

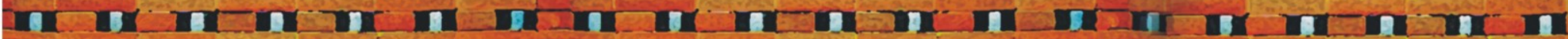

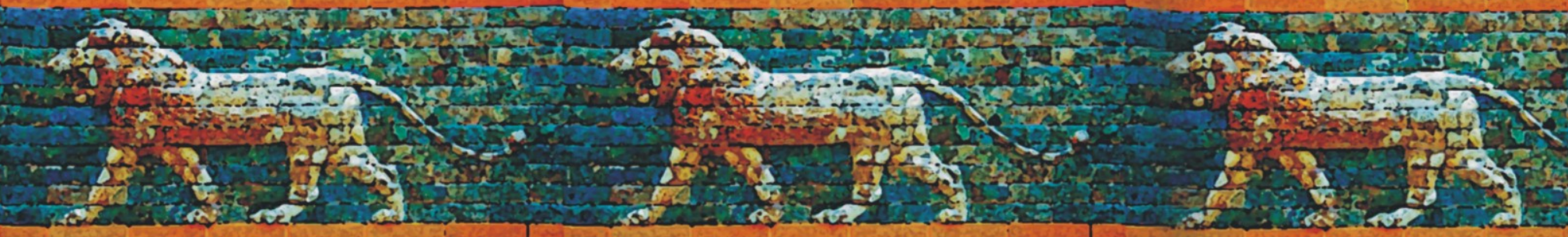

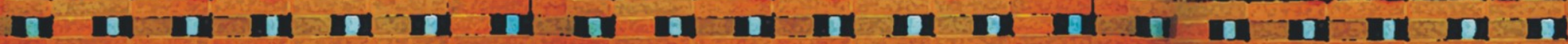

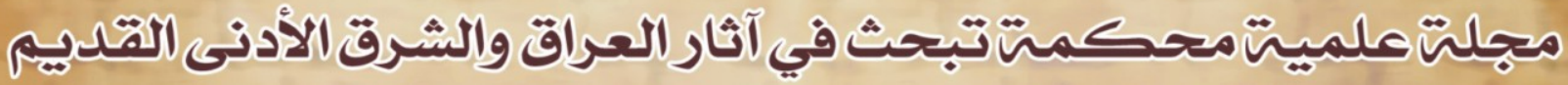

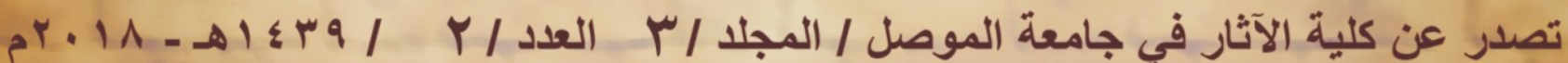




رقم الإِيداع في دار الكتب و الوثائق ببذداد

relr (IVIr) (لسنة 



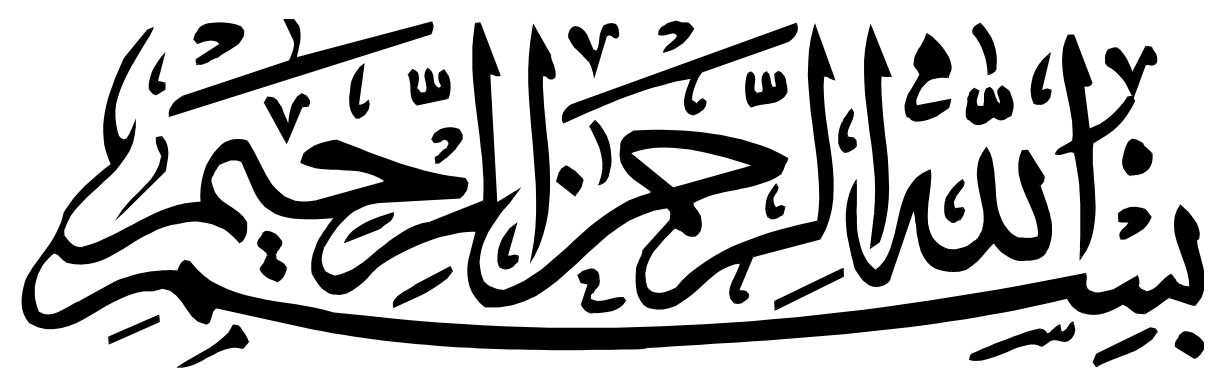





$$
\text { أ.د. علي ياسة التمرير الجبوري }
$$

أ.م.د. فيسان هوفق رشيد النعيشي سكرتير التصرير
أ.د. صفوان ساهي سعيد الرفاعي نائب رئيس التمرير

الألعناs

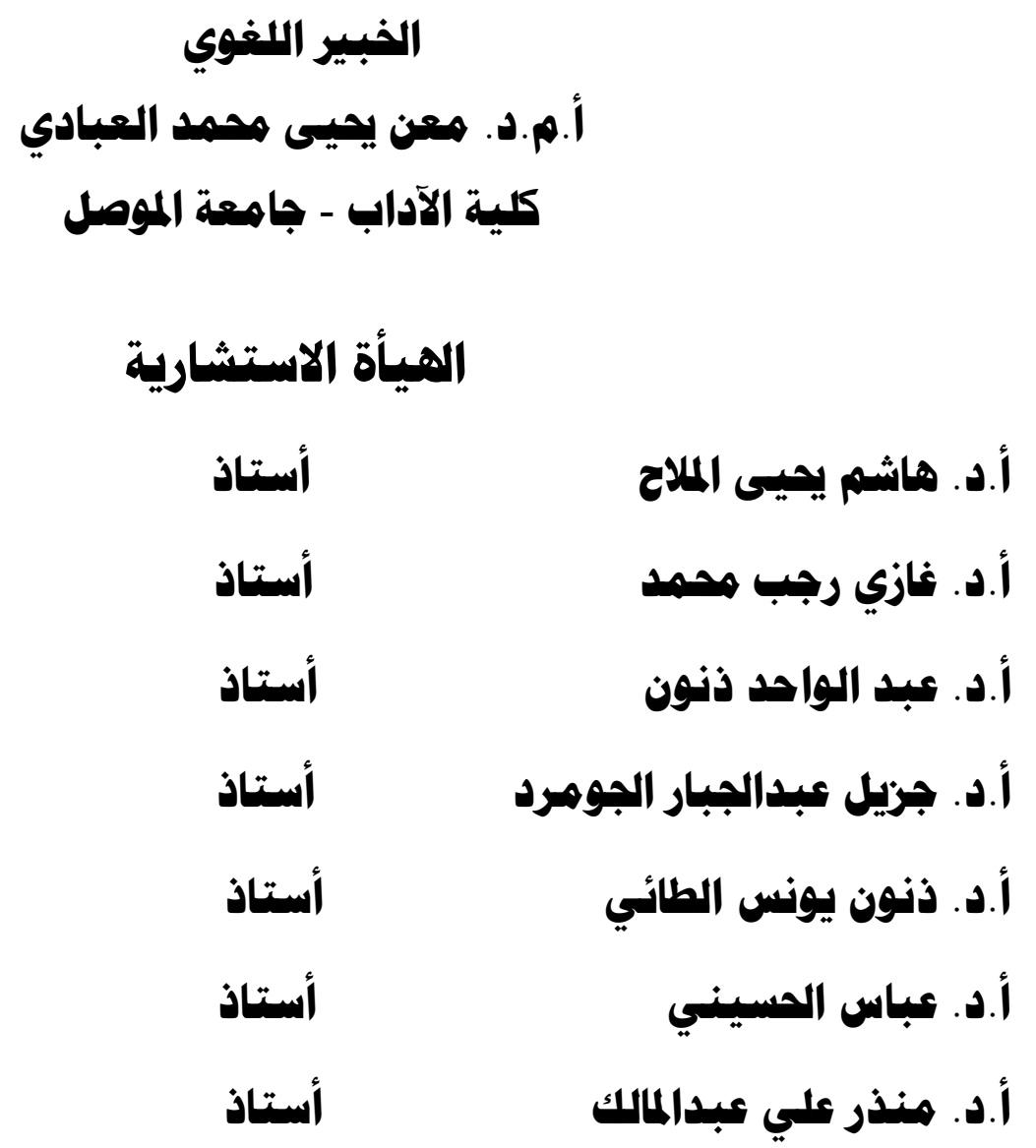

جاهمة الموصل

جاهمة بغداد

جامعة الموصل

جاهعة الموصل

جاهمة الموصل

جاهعة القادسية

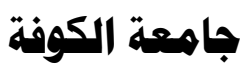

\author{
أ.د. شعلان كاهل اسماويل \\ أ.د. عاهر عبدالله نجم الجُميلي \\ أ.م.د. زهير ضياء الدين سعيد الرفاعي

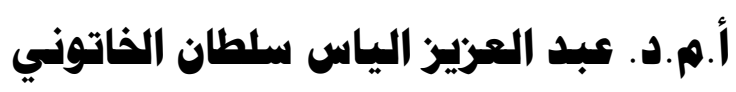





\section{قواعد النشر في المبلة}

• يشترط أن يكون البحث ضهن الاختصاصات التي تُعنى بها المجلة • يشترط على الباحث الالتزام بالموضوعية و المنهج العلمي في البحث و التحليل ،و أن يلتزه بشروط البحث العلمي هن حيث التبويب و استعمال الهواهش و الإشارة إلى المصادر و المراجع وفق طريقة هنهجية و احدة ،و في

$$
\text { آخر البحث }
$$

• يشترط على الباحث هراعاة الجوانب الشكلية و الاهتهام بسلاهة لغة البحث هن الأخطاء اللغوية و المطبعية

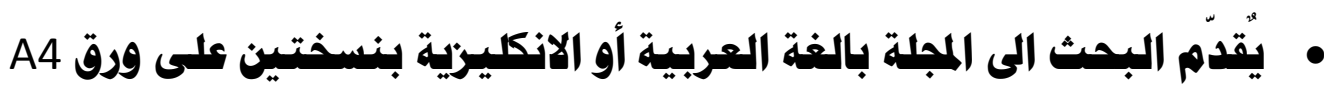
• يرافق البحث في أوله هلخص" باللغة الانكليزية على أن لا يريد عدد كلماته

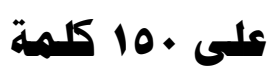

• يشترط أن لا يكون البحث قد نشر او قبل للنشر في أيّة دورية علمية داخل

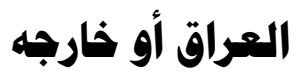

• يشترط على الباحث أن لا تتجاوز عدد صفحات بثثه عن ro صفحة • يشترط في البحث أن تكون المشاهد و الأشكال الفنية المرافقة له عالية الجودة • أصول البحث المقدهة إلى البلة لا ترد أو تُسترجع سواء نشرت أم لم تنشر • تعتمد المجلة هبدأ التمويل الذاتي وتهدد أجور النشر في ضوء الأسعار السائدة 



\section{ثبت المتويات}

\begin{tabular}{|c|c|c|}
\hline 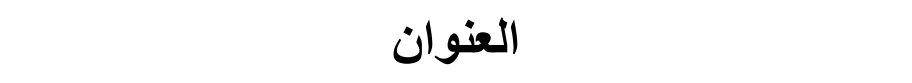 & اسم الباحث & الصفحة \\
\hline تؤطئة & أ.د. علي ياسين الجبوري & $r_{-1}$ \\
\hline قر اءة النص المسماري وتحليله ( تحقيقه ) & 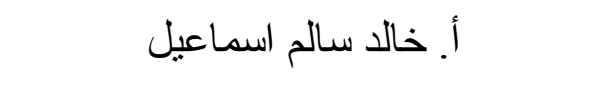 & $r \cdot-r$ \\
\hline آداب تتاول الطعام و الثر اب عند المصريين القدماء & أ.د.حسين ظاهر حمود & $\left\{\tau_{-}\right\}$ \\
\hline مدن و مو اقع جغر افية نسبت لأسماء النباتات في ضوء واء المسية & أ. م. د. دؤيد محمد سليمان الدلّيمي & $\Lambda_{-} \leqslant \vee$ \\
\hline مشاعر الأنسان و انعكاسها في الخطاب الرسميّ في المملكة & أد. د. صفو ان سامي سعيد & $1 Y \varepsilon_{-} \wedge 9$ \\
\hline " المجاز العقلي في اللغة الأكدية & أ.م.د. ز هير ضياء الدين سعيد الرفاعي & $1 \leq \cdot-10_{0}$ \\
\hline أثز البيئة في اقتصاد بلاد الر افدين إبان عصور ما قبل & أ.م.د. حسين يوسف حازم & $17 \cdot-1 \leq 1$ \\
\hline حقوق الجار المتضرر في القانون العر اقي القديم & أ. م. د عبدالرحمن يونس عبد الرحمن & $\left|V A_{-}\right| 7 \mid$ \\
\hline الأسطورة بوصفها مصدر الدر استة التاريخ أسطورة قايين & أ. م.د. محمد العلامي & $117_{-} 1 \vee 9$ \\
\hline الخصائص المعمارية المشتركة في تخطيط البيمارستان & أ...د. اكرم محمد يحيى & $Y Y \varepsilon_{-} \mid \wedge V$ \\
\hline دار غز الة في حي الجديدة بمدينة حلب في العهد العثمانيّ & د. محمد خضر محمود & $Y \leq \varepsilon-Y Y_{0}$ \\
\hline 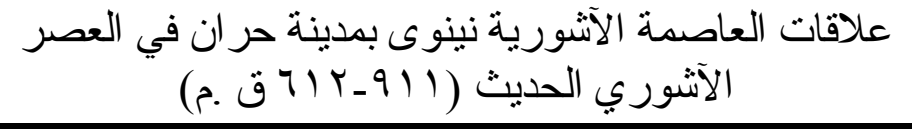 & د. إيمان هاني العلوش & YON- $r \leqslant 0$ \\
\hline الابن البار و الابن العاق في المجتمع البابلي & 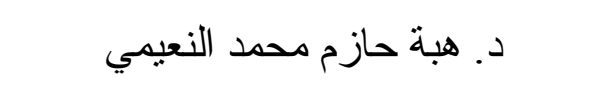 & $r V \varepsilon_{-} r \circ 9$ \\
\hline 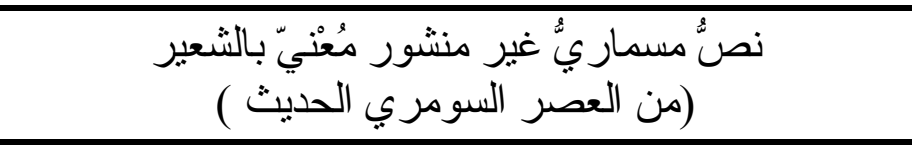 & د د معاذ حبش خضر & YQY_rVO \\
\hline عبار ات التهديد في رسائل العصر البابليّ القديم & د. دـ رامي عبد الحكيم قاسم العبادي & $r \cdot T_{-}+r^{2}$ \\
\hline
\end{tabular}





\begin{tabular}{|c|c|c|}
\hline عقود إيجار غير منشورة من عهد الملك البابلي سمسو -إيلونا & د. ياسر جابر خليل & V.r- • \\
\hline (در اسة في ضوص رُّل مدينة أومّا (جوخة المصادر المسمارية) & د. أباذر راهي سعدون الزيدي & וTس_R \\
\hline صياغة عقود الدين في العصر البابليّ القديم & م. أحمد ميسر فاضل & $r v \varepsilon_{-} r 00$ \\
\hline الحفاظ على المباني الأثرية المشيدة بالحجارة من العو امل & م: رنا و عد الله مهدي & rqr_rvo \\
\hline الصائغ وحرفته في العر اق القديم في ضو ه المصادر & م.م .ر عد سالم محمد المعماري & ש. \\
\hline
\end{tabular}

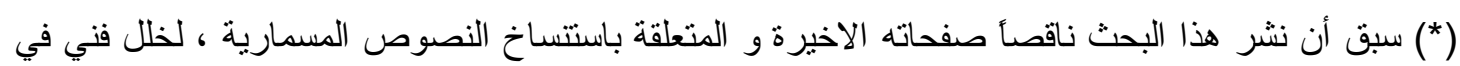

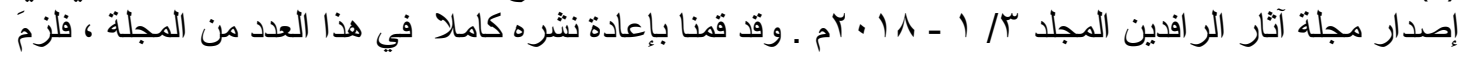





\section{توطئة}

أ.د. علي ياسين الجبوري

\section{رئيس هيأة التحرير}

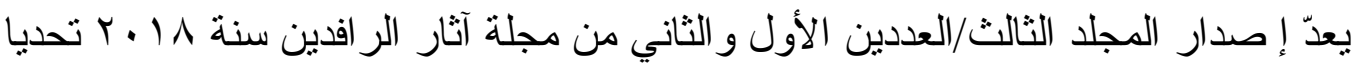

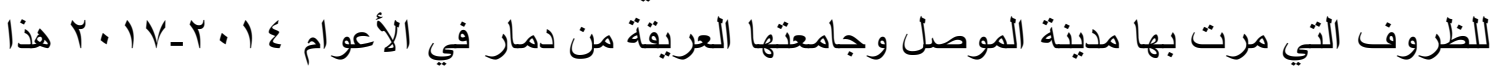

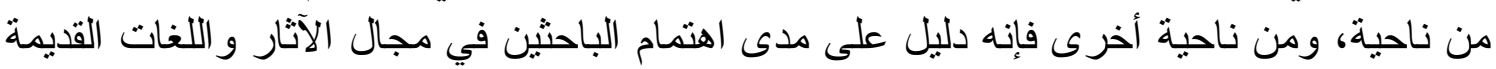
وتقتهم بمجلة آثار الر افدين

تهتم المجلة بجميع الأبحاث التي تعالج مو اضيع ذات علاقة بالمبن المعارف التاريخية و السياسية و الحضارية لبلاد الر افدين و الثرق الأدنى القديم وللعصور القديمة و الإسلامية كافة التهاف

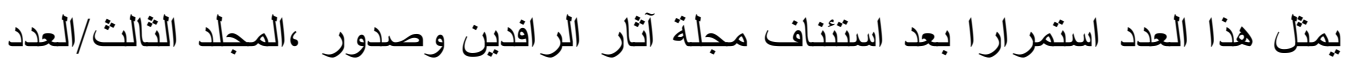

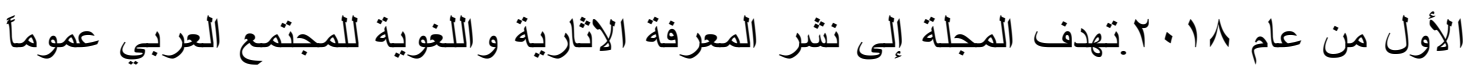

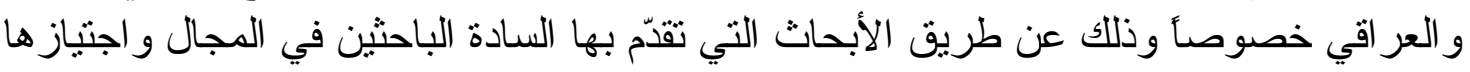

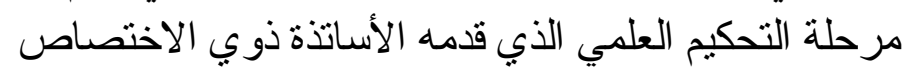

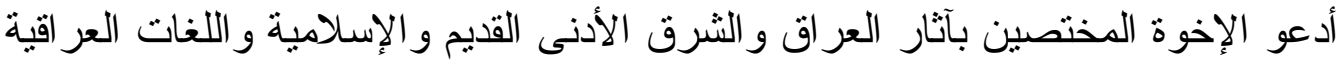

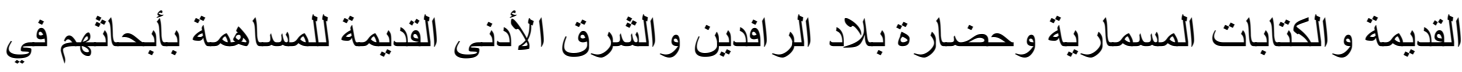

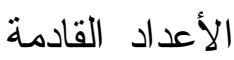

ومن الله التوفيق 



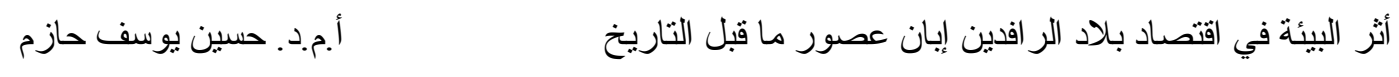

أثر البيئة في اقتصاد بلاد الرافدين إبان عصور ما قبل التاريخ

أ.م.د. حسين يوسف حازم

كلية الآثار - - جامعة الموصل

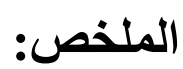

تعد البيئة أحد أهم العو امل الاساسية و الرئيسة وذات تأثنير مباثر في الحياة الاقتصاد لما

لها من انعكاسات كبيرة وهامة في تحديد ورسم جو انب هذه الحياة وتعيين مسار اتها الو اضحة و الحقيقية ـ وقد تلازم تأثنير البيئة في واقع الحياة الاقتصاد منذ أقدم العصور وتركت أثنارها عليها بشكل و اضح وجلي . ووفقا لتأثيرات و تغيرات البيئة وتأثير ها المباثر على حياة ونشاطات الانسان فقد تحددت أسس الحياة الاقتصاد واركانها التي مثلت الثريان الرئيس و الاساس لحياة الانسان ، فوجود وقيام الحياة البشرية وقيامها يعتمد بشكل أساس على الحياة الاقتصاد و التي اتسمت بالتغير و التطور ومعها تغيرت حياة الانسان وتظورت و على أساسها ومضمونها قامت العصور وتحددت مسار اتها وصور ها وفق هذه الحياة ، و التي شكلت البيئة ركنها الهام و الكبير .

تتاول البحث المظهر العام للبيئة في بلاد الر افدين وخصائصها العامة وتطور اتها في مرحلة عصور ما قبل التاريخ منذ أقدم العصور الحجرية ـ كما تتاولنا أثر البيئة الطبيعية في جوانب الحياة الاقتصاد لبلاد الر افدين ، و لاسيما الزر اعة و الصناعة و التجارة و التطور ات التي حدثت فيها وأثز البيئة وتحديد مسار اتها العامة وبشكل منفصل التأثير الكبير و المباثر على تلك الجو انب وفق معطيات ونتائج الأبحاث و الأدلة الأثرية و المناخية و البيئية المتعلقة بها و الاستتناجات

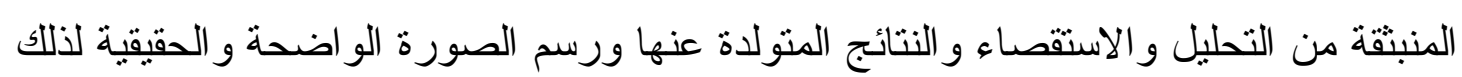
التأثير في الاقتصاد وجو انبه إبان عصور ما قبل التاريخ في بلاد البلاد الر افدين . 


\title{
Impact of Environment on Mesopotamian Economy During Prehistory
}

\section{Assistant Professor Dr. Hussein Yousif Hazim \\ College of Archaeology - University of Mosul}

\begin{abstract}
The environment is one of the most important and fundamental factors and has a direct impact on economic life because of its significant and important implications in defining and mapping aspects of this life and set clear paths and reality. the impact of the environment on the reality of economic life has been associated since ancient periods and its effects have been clearly and clearly revealed. according to the effects and changes of the environment and its direct impact on human life and activities, the foundations and pillars of economic life, which were the main and basic artery of human life. the existence and existence of human life depends mainly on economic life, which was characterized by change and development of the person who lived and relied on it and one the basic and content of the ages and determined their paths and images according to this life. The research examined the general appearance of environment in Mesopotamia and its general characteristics and developments during the prehistoric period since the earliest stone ages we also discussed the impact of natural environment or aspects economic life if Mesopotamia mainly agriculture, industry and trade the impact of the environment on it and its general Path ways especially during the Neolithic period and its after math. We discussed in detail the significant and direct impact on these aspects according to the data and results of research and archaeological evidence climate and environment related to them and the conclusions arising from the analysis and investigation and
\end{abstract}


the results generated by it and draw clear picture on the economy and its aspects during the prehistoric times in Mesopotamia.

\section{المقدمة:}

تركت البيئة أثزها الكبير و الو اضح في الحياة الاقتصاد لبلاد الر افدين منذ أقدم العصور

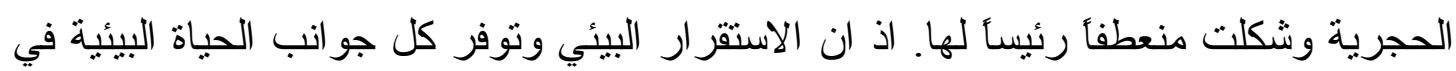
بلاد الر افدين في حقبة العصريين الحجريين القديم و المتوسط قد ظهرت اثناره الكبيرة و الو اضحة في استقر ار حياة الانسان وتكيفه المباثر مع تلأك البيئة ، و لاسيما في المنطقة الثمالية من بلاد

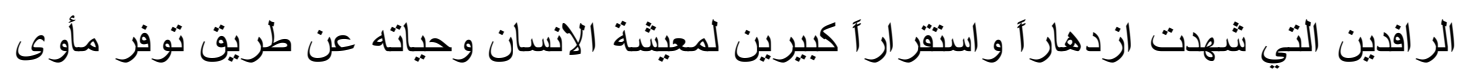

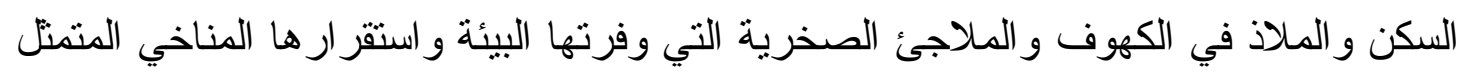
بتوفر الامطار الغزيرة التي أعتمد عليها الانسان وكذلك الحيوانات التي متلت جانتباً أساسا"

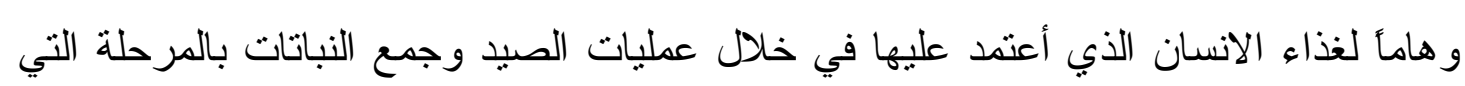

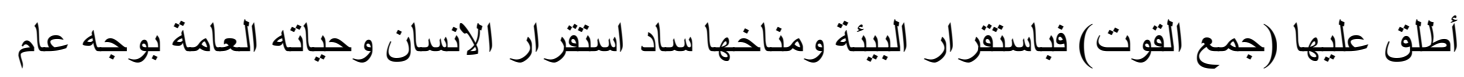
في الحقبة التي أطلق عليها (الفترة الجليدية الثالثة) التي تمنلت بسيادة الاستقر ار البيئي و المناخي

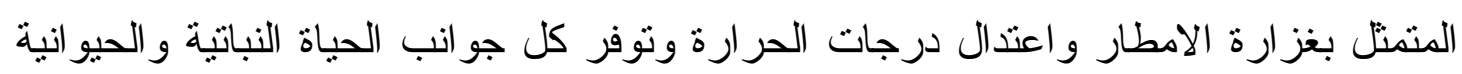

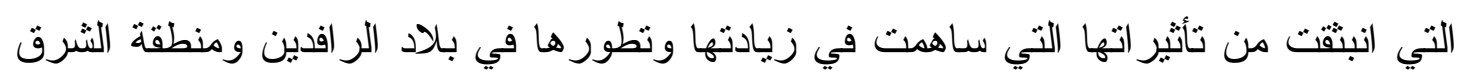

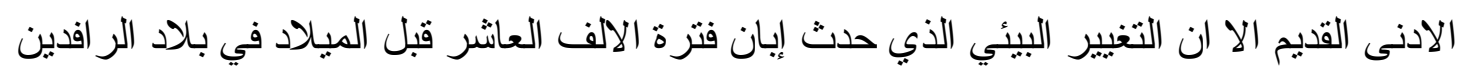

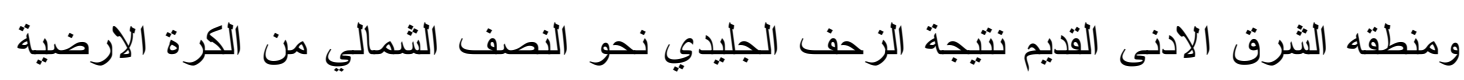

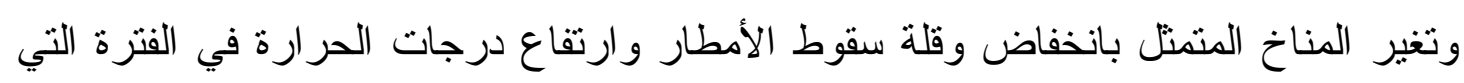

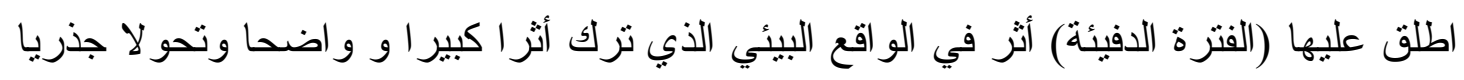

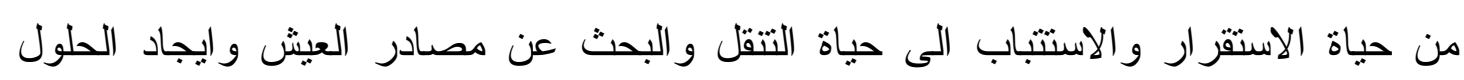

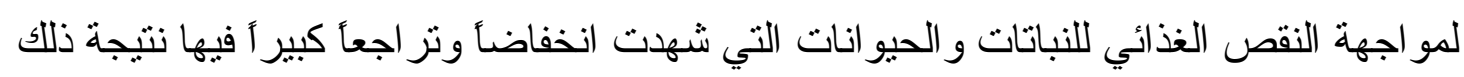

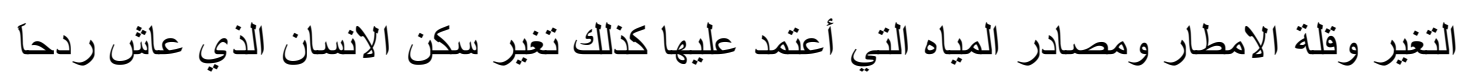

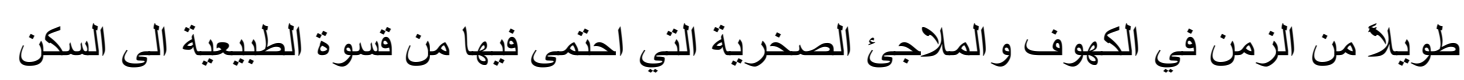

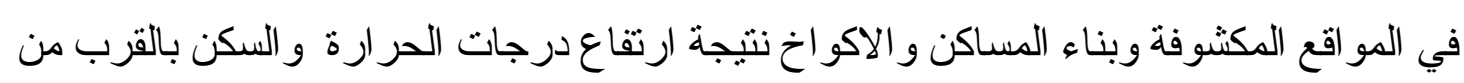

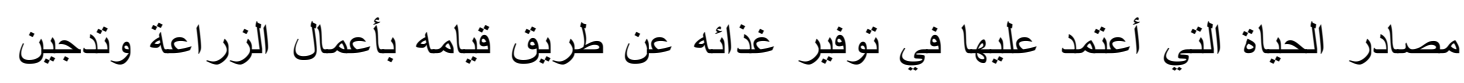

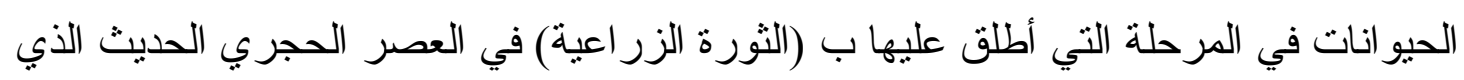

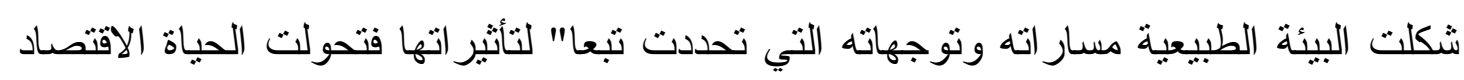
للإنسان في بلاد الر افدين ومنطقة الثرق الادنى القديم من حياة الجمع والالتقاط إلى الإنتاج 
و ايجاد البدائل لحياته الاقتصاد وجانبها الغذائي المتمثل بقيام الزر اعة وتكجين الحيوانات وقيام

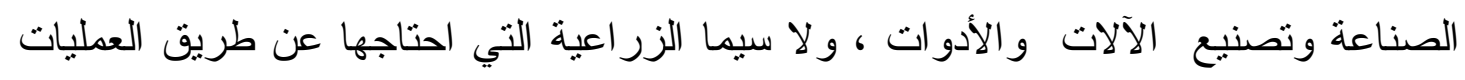
الزر اعية فضلا" الأدوات المنزلية التي احتاجها في حياته اليومية المباثرة وكذلك القيام بعمليات

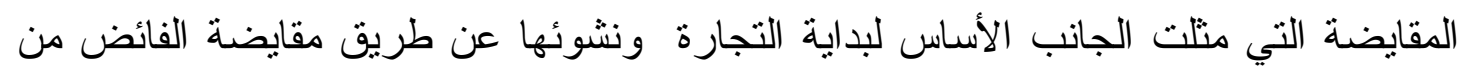
المنتوج بالمو اد التي احتاجها الانسان وغير المتوفرة في بيئته أو النادرة.

\section{المظهر العام لبيئة يلاد الرافدين وخصائصها العامة وتطوراتها}

تعد البيئة الطبيعية أحد أهم العوامل الاساسية في تكوين ونشوء الحضارة ونشوئها الناتجة من تفاعل الانسان مع بيئته الطبيعية وتحديه لها وتشخيرها لخدمة وان كيفية التفاعل و اسلوب التحدي وطر ائق تسخير الطبيعة لخدمة الانسان هي التي تكسب الحضارة طابعها الخاص وما ينطبق على الحضار ات المعاصرة يصدق على الحضارات القديمة ومنها حضارة

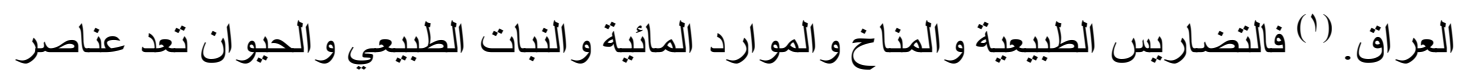
اساسية للبيئة الطبيعية وهي نتشكل بمجملها مرنكز ات هامة في بناء الحضارة وتكوينها وتحديد مسار اتها وتوجهاتها. فقد تجعل تضاريس هذا البلد مثلا منه إقليما مفتوحأ تسهل الهجرة اليه كما فيا

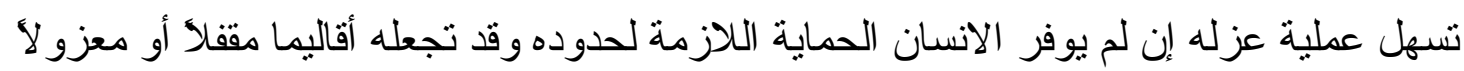

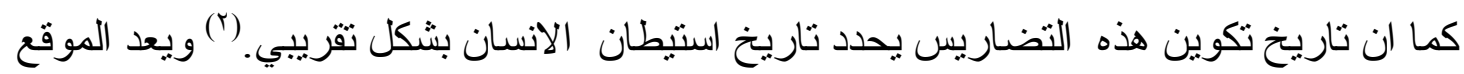

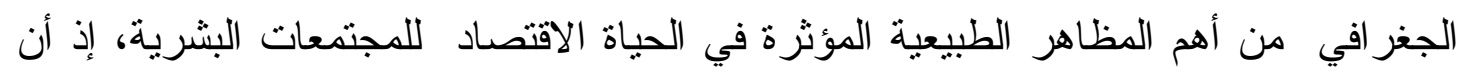
الموقع الجغر افي و هو موقع المكان بالنسبة لخطوط الطول ودرجات العرض ذات القيمة الثابتة

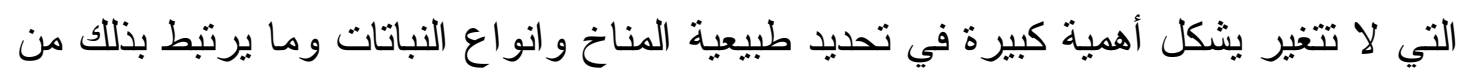
توزيع السكان ونشاطاتهم المختلفة في الموقع، كما يمنل موقع المكان بالنسبة للظو اهر الطبيعية

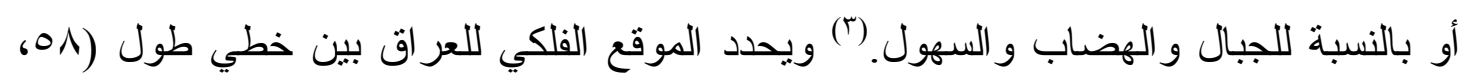

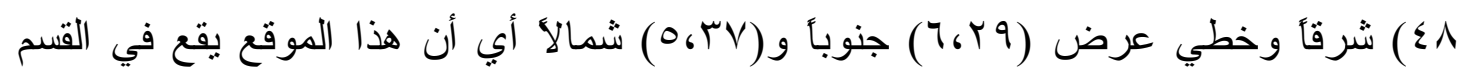

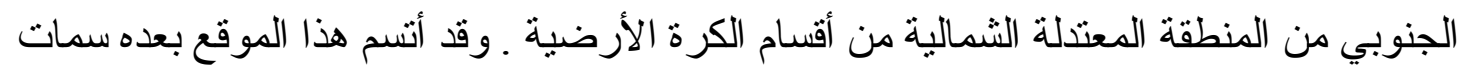
منها الطقس الذي تتفاوت درجات الحرارة بين أقسامه الطبيعية (الثمال و الوسط و الجنوب) فضلا عن اختلاف كميات الامطار الساقطة، إذ إن المنطقة الثمالية أغزر مطر أ من المنطقتين

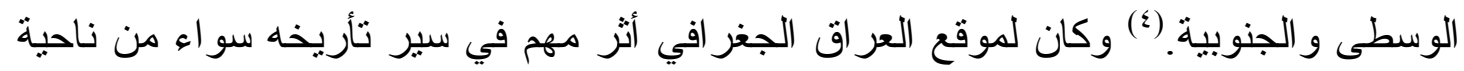
الطقس و المناخ و الزر اعة و الحياة الاقتصاد بوجه عام أم من ناحية تركيب سكانه و اتصالاته

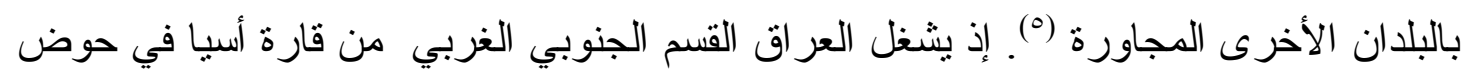

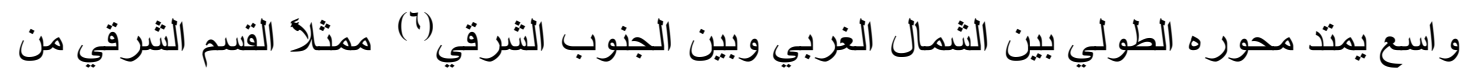


الوطن العربي في منطقة انتقال بين مناخ الصحر اء الجاف ومناخ البحر المتوسط الرطب وتبو أ

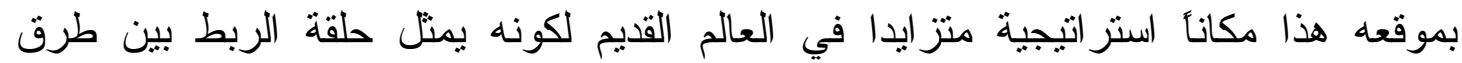

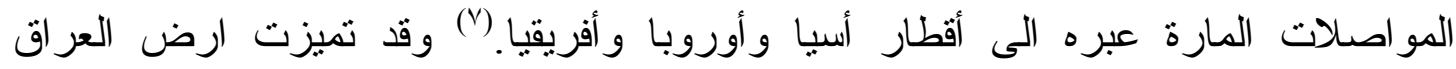
بتضاريس منتوعة كان لها الأثر البالغ في الحياة الاقتصاد للإنسان العراقي القديم منذ القدم وتتباين هذه التضاريس في جميع الجهات من الثمال الى الجنوب ومن الثرق الى الغرب ،

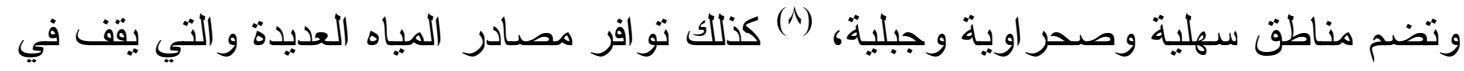
مقدمتها نهر ا دجلة و الفرات ورو افدها و الدياه الجوفية ومياه الأمطار و التي كان لها الاثر الكبير

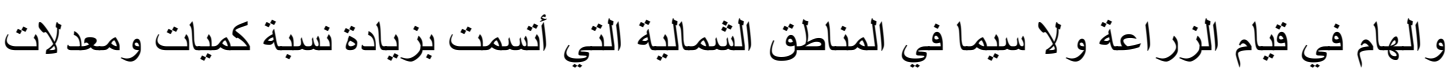

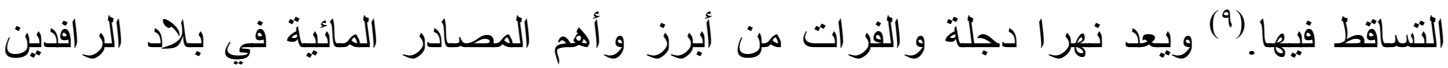

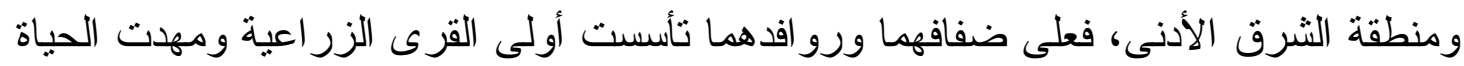
الزر اعية بدور ها لظهور أقدم الحضار ات البشرية، علاوة على دورهما الكبير في المواصلات

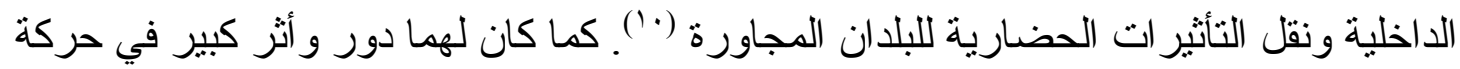

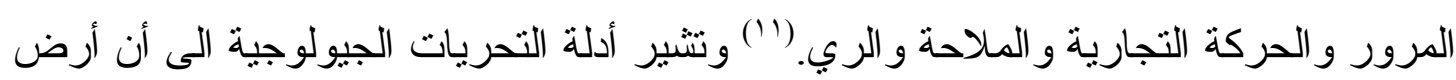

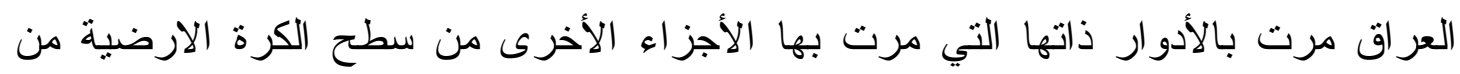

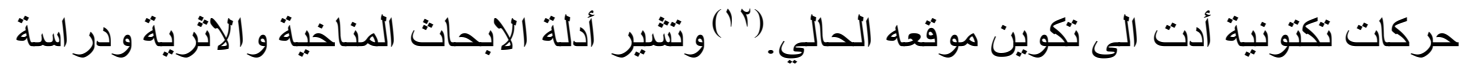
المخلفات النباتية و الحيو انية لمو اقع قرى ومستوطنات بلاد الر افدين الى عدم حصول تغيرات

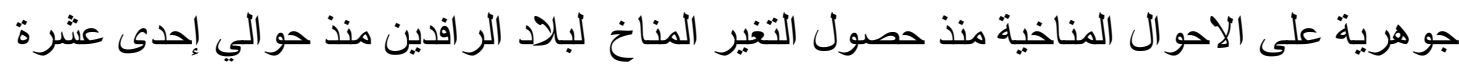

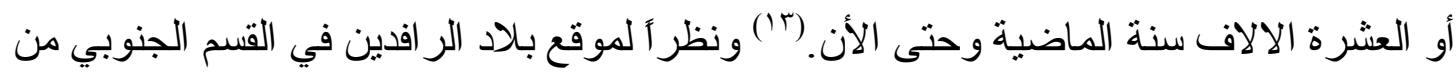

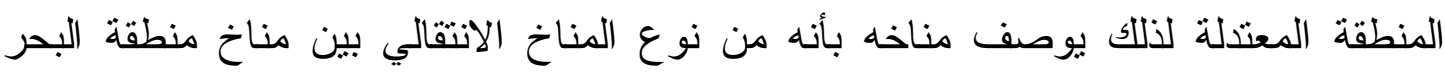

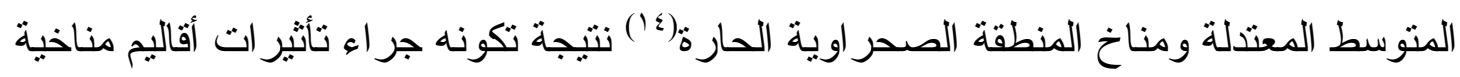

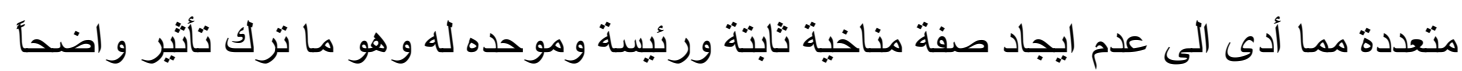

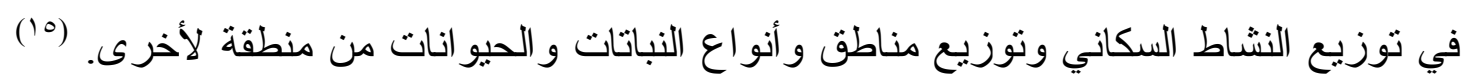

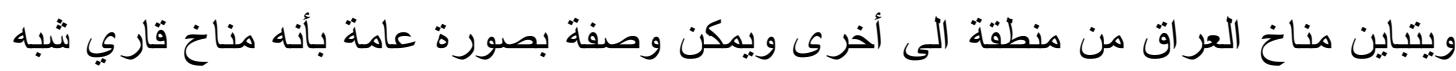

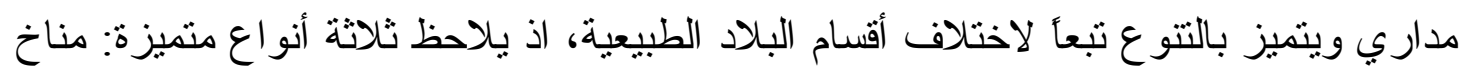

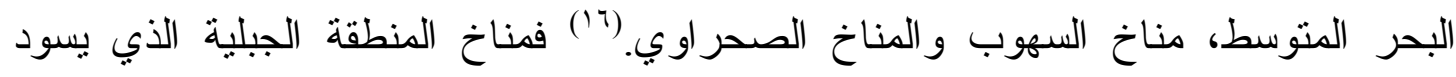
المناطق الثمالية شبيه بمناخ البحر الابيض المتوسط الذي تميز ببرودته وانخفاض درجة

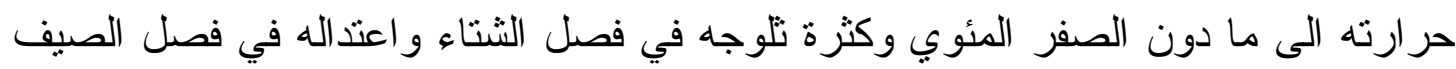
وغز ارة امطاره.('ا أما منطقة السهوب التي تنود المنطقة المتموجة أو الثبه جبلية فيسودها المناخ الانتقالي بين مناخ البحر المتوسط و المناخ الصحر اوي الحار وتقل فيها لأمطار قياسأ مع لئه 
المنطق الجبلية.(^) أما المنطقة الصحر اوية التي تتمل منطقتي السهل الرسوبي و الهضبة الغربية

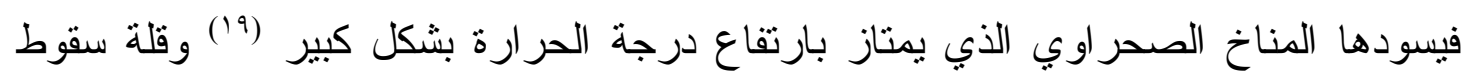

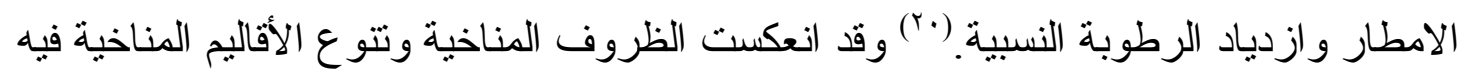

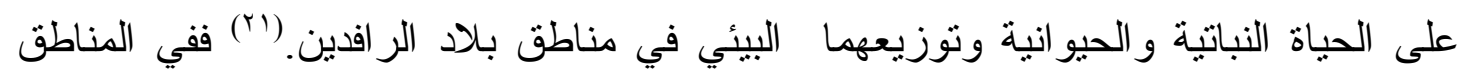
الثمالية و الثمالية الثرقية من بلاد الر افدين و لاسيما المنطقة الجبلية نوجد أنواع مختلفة من بنائل

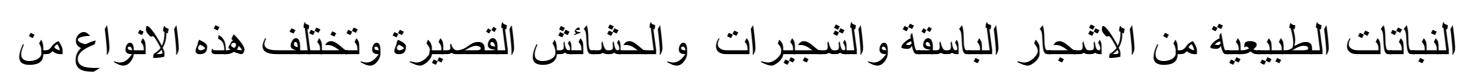

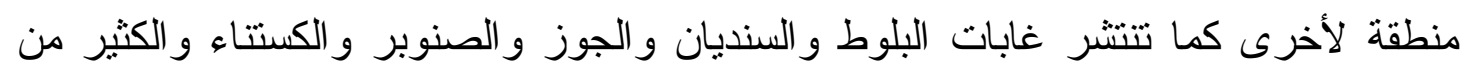

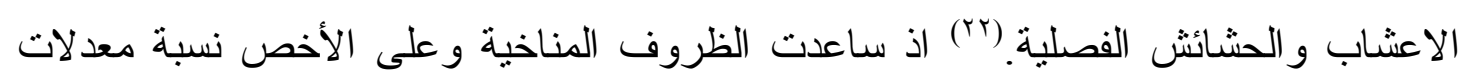

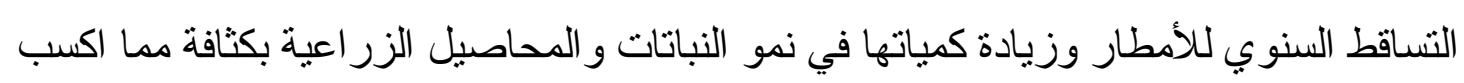

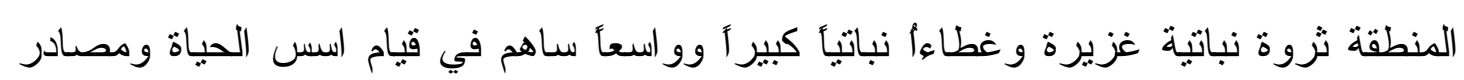

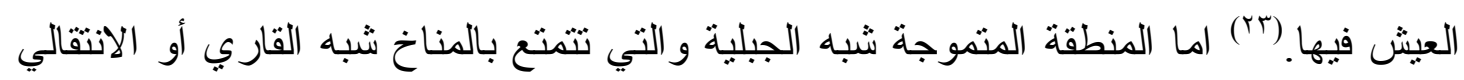

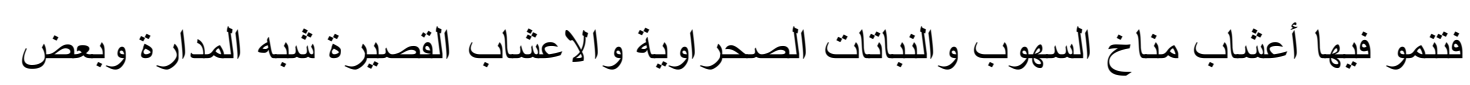

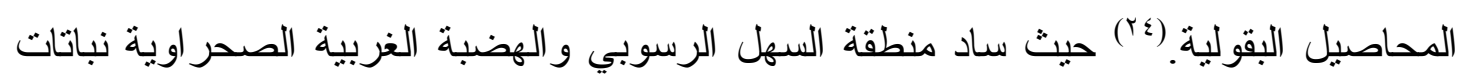
ذات قيمة غير غذائية أو محدودة غذائياً بحكم الظروف المناخية السائدة في المنطقة المتمنلة بقلة سقوط الامطار و ارتفاع درجات الحر ارة ونسبة الجفاف العالية و التي حالت دون حصول غطاء فئاء

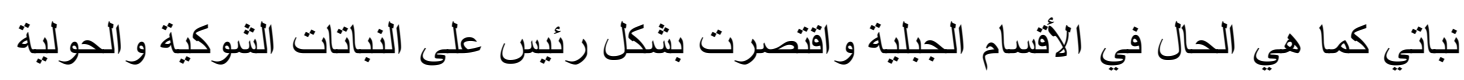

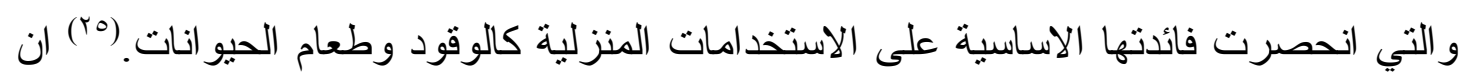

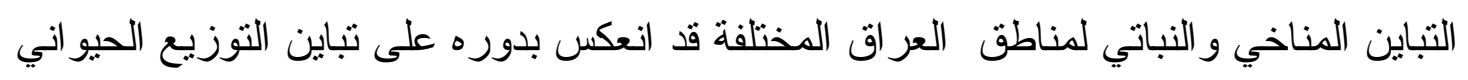

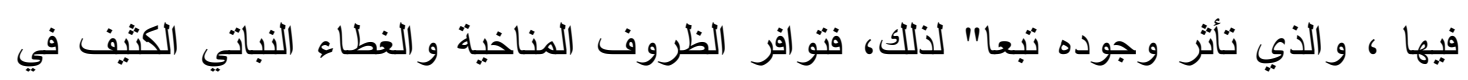

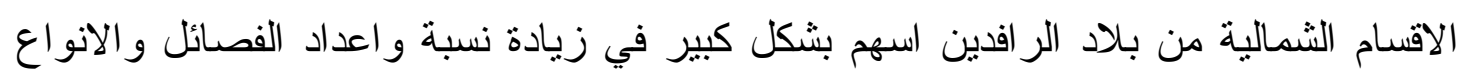

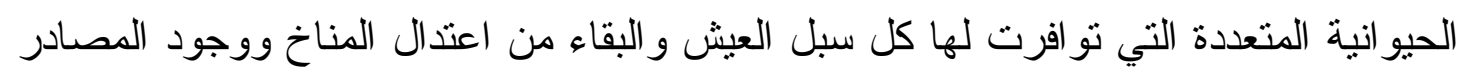

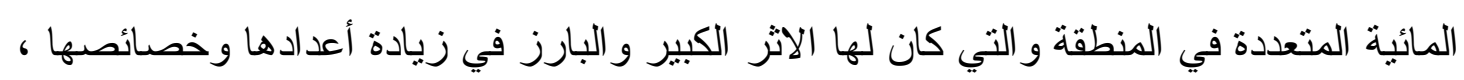

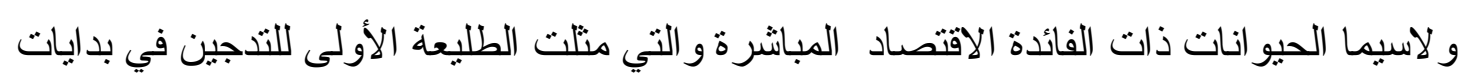

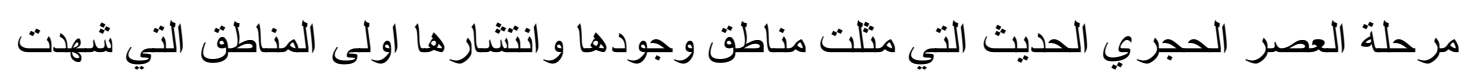
قيام عمليات التدجين الأولى في العراق وهذا ما اكدته و اثثتته نتائج التتقيبات والتحريات الاثرية.(7) في حين ادت الظروف المناخية المتذبذبة و الصعبة وبشكل أساس قلة سقوط الأمطار و وارتفاع درجات الحرارة وزيادة نسبة الجفاف وقلة المصادر المائية المقتصرة على الأنهار

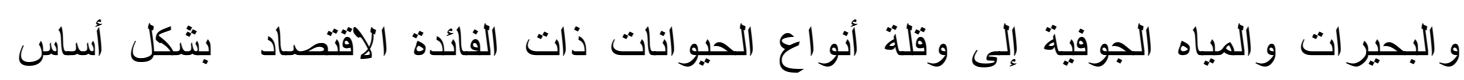

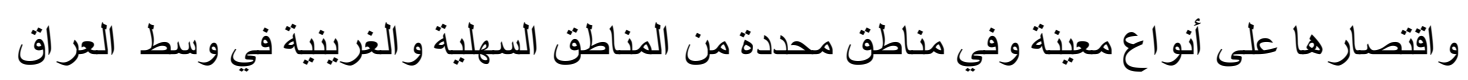


وجنوبه ، و التي شهدت عمليات التّجين في مر احل لاحقة من العصر الحجري الحديث كما أثارت نتائج أعمال التنقيات و التحريات الاثرية التي كثفت عن عظام حيوانات مدجنة وبرية تقف الاغنام و الماثنية و الثور والخنزير في مقدتها فضلا عن أنواع عديدة من الأسماك

و الطيور ، و لاسيما في مناطق الاهو ار و المستتقعات التي تتو اجد فيها بشكل كبير وبارز. (rv)

\section{أثر البيئة في الحياة الاقتصاد لبلاد الرافدين}

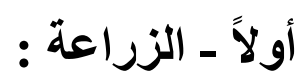

يعد ابتكار الزراعة وتطوير مسنلزماتها وتهيئة شروطها أهم المنجزات التي حققها

الانسان في مسيرة حياته الطويلة إبان العصور القديمة اطلاقأ وعدت نتائجها الحد الفاصل ما بين عهود البدائية وعهود الحضارة في تاريخ الانسان، فالزر اعة هي الركن الاساس في حضارة الانسان وهي الاساس المادي الصلد لأوجه التطور ات المختلفة التي عاثتها الحضارة الإنسانية في جو انبها الفكرية و المادية. وقد قادت الزراعة إلى سلسلة ابتكار ات منها تهجين النباتات وتدجين الحيوانات وحصول تغير ات اجتماعية و اضحة قادت الى وضع أسس الحضارة وأركانها.(^^) وتعد البيئة وتأثنير اتها ذات أثز كبير في الزر اعة وتطورها، اذ تمنل المرتكز الأساس و العمود الفقري الذي تقوم عليه الزر اعة فالبيئة بأشكالها وصور ها كافة تحدد شكل الحياة الاقتصاد وبوجه خاص الزر اعة للإنسان الذي يعد وجودهوديمومة حياته قائماً عليها وطبقاً لذلك تعتمد نشاطات الأنسان وفعالياته التي يسعى بها إلى تأمين مصادر عيشه و استمر ار بقائه. لقد كان لتأثير ات البيئة في بلاد الر افدين كأية بقعة في العالم الأثر الكبير و البالغ في تحديد مسار اته الاقتصاد وبوجه خاص الزراعة. وكما أثرنا أنفا" الى طبيعة تضاريس بلاد الر افدين وطبو غر افيتها و اقاليمها المناخية يمكننا القول إن تأثير البيئة في زر اعة بلاد الر افدين يتحدد في عاملين أساسين هما : طبيعة طبو غر افية وجغر افية أقسامه الثلاثة في الثمال و الوسط و الجنوب و التأثير ات المناخية لتلك الاقسام و اقاليمها المناخية. وقد كان للإنسان في بلاد الر افدين وجهوده دور كبير في تسخير البيئة ومواردها لتحقيق ونوفير سبل عيشه وبقائه وديمومته وبوجه خاص في العصر الحجري الحديث حيث شهدت البيئة تغيرات كبيرة وجذرية نتيجة التغبير المناخي الذي حل في الالف العاثر ق.م وما ألت اليه الاحو ال المعيشية للإنسان الذي كان يعتمد على ما تجود به البيئة و الطبيعة من خير ات ومو ارد كثيرة ومنتو عة ليصبح بعد ذلك نتيجة لتلك الظروف الصعبة و القاسية منتجأ للطعام لأول مرة بعد ان كان مستهلكأ له.(99) فكما أثنرنا أنفا" كان للبيئة ودور ها الأثز الكبير و الهام في قيام أسس الزر اعة وأركانها في الأقسام الثمالية و الثمالية الثرقية من بلاد الر افدين التي تشكل زهاء(· r \%) من مساحة البلاد الكلية و التي تمتذ في جهات 
البلاد الثمالية و الثمالية الثرقية لغاية حدودها المشتركة مع ايران وتركيا وسوريا وتثكل جبالها جز عأ من سلاسل جبال ز اكروس - طوروس ومن النطاق الجبلي العام المسمى بالنظام الالبي.(•) وبالتالي فهي جز ء من هذه المنطقة التي تتمتع بغطاء نباتي كثيف وحياة نباتية زاهرة

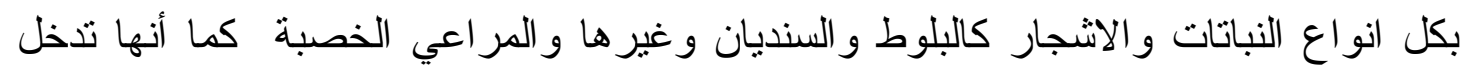

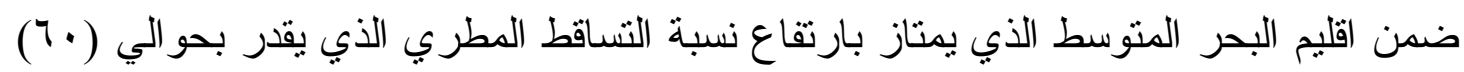

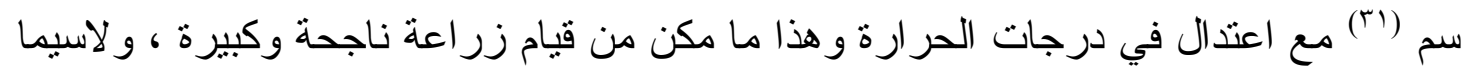

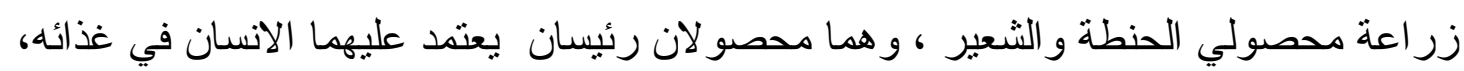

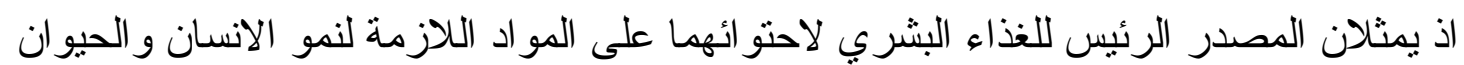

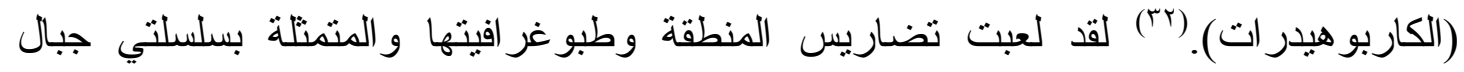
ز زكروس في الجهة الثمالية الثرقية و طوروس في الجهة الثمالية من بلاد الر افدين دور أ هامأ

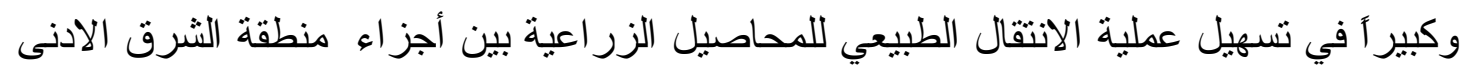

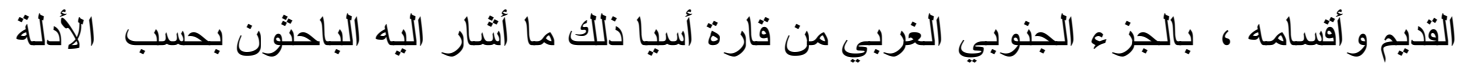

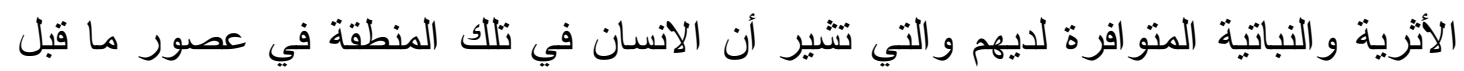

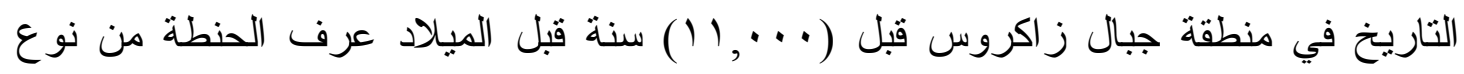

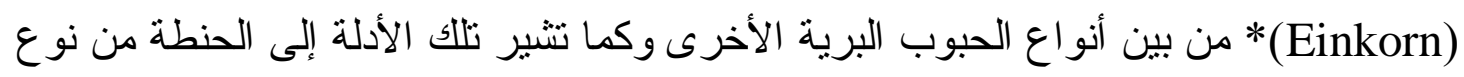
(Emmer)

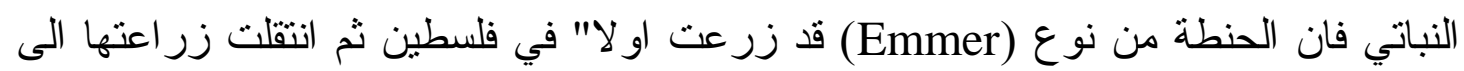

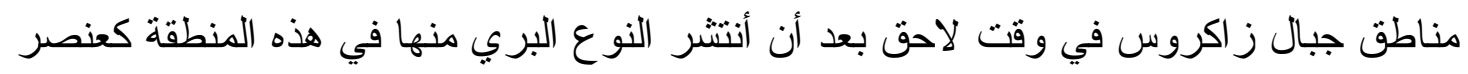

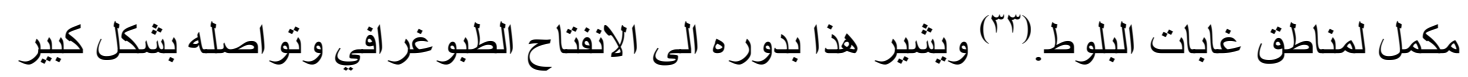

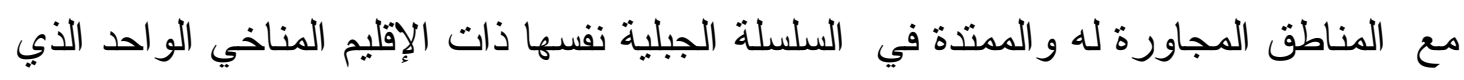
لعب دورأ هامأ في إكساب المنطقة كل مصادر العيش وتوفير الاجواء و الظروف البيئية و المناخية الملائمة للزر اعة وتطور ها وازدهار ها مع وجود الأسلاف البرية للعديد من المحاصيل

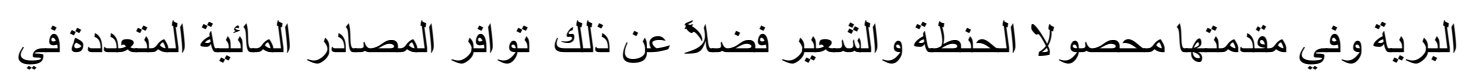

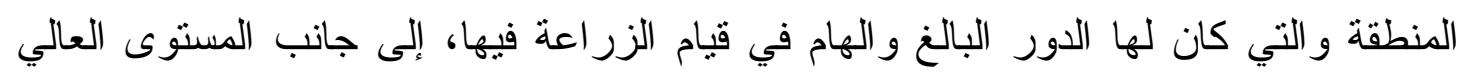
للتساقط المطري الذي تمتعت به المنطقة و اختر اق رو افد نهر دجلة للعديد من اقسامها و التي تمده

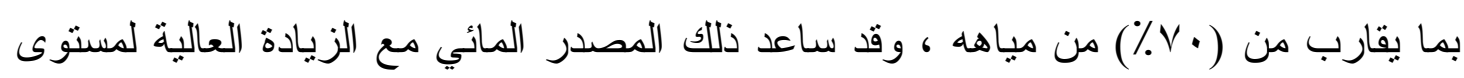

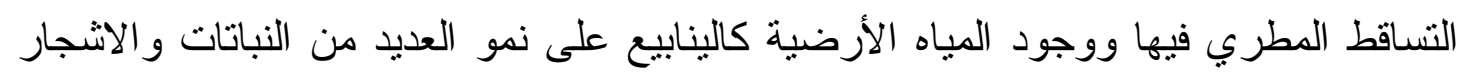
فضلا" عن الحبوب التي تتمو في السهول و الوديان و انتشار الغابات على سطوح الجبال وتكاثر التران الحشائش و النباتات الطبيعية الأخرى وغير ذلك من مستلزمات الحياة. وقد شجعت تلك الظروف 
البيئية في هذه المنطقة و التي أسهمت الزر اعة فيها مساهمة كبيرة وفاعلة على ترك الانسان لسكن الكهوف و المغار ات و الملاجئ الصخرية و اللجو ء إلى المو اقع المكثوفة تدريجيأ و السكن

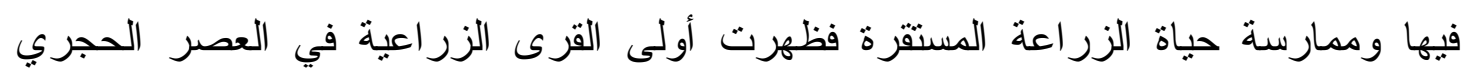
الحديث. () وقد كان للبيئة و عناصر ها أثز و اضح وكبير في الزر اعة التي انتشرت في المنطقة الوسطى و الجنوبية من بلاد الر افدين المتمثلة بمنطقة السهل الرسوبي في الوسط و الجنوب و والتي لتي

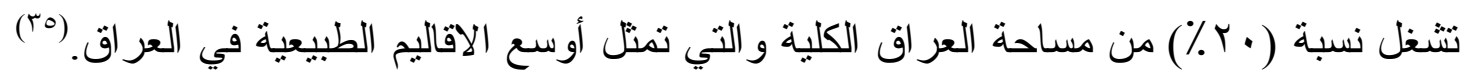
ونظر أ لطبيعية المصادر المائية في المنطقة و المتمثلة بكمية النساقط المطري و الذي يقدر بحدود

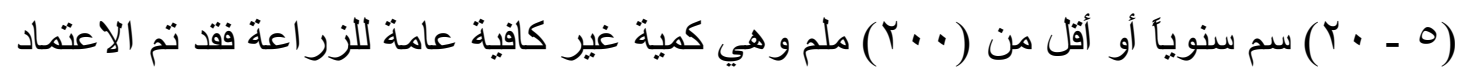

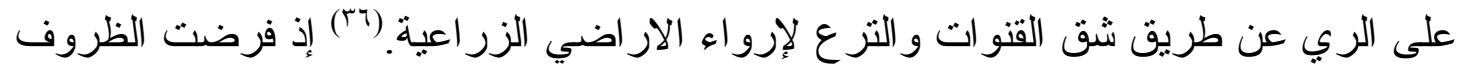

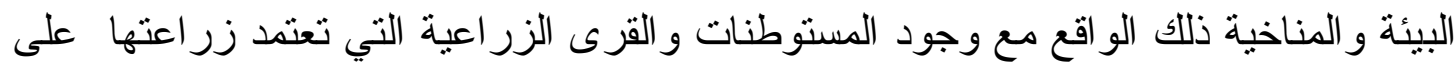

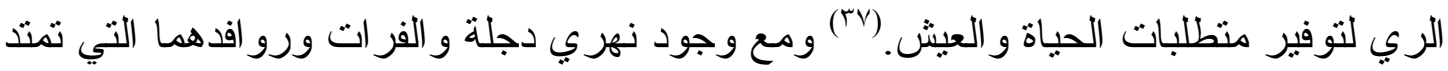
على طول أقسام المنطقة و أجز ائها يلاحظ ان الاثر البيئي في الزر اعة في المنطقة بشكله هذات

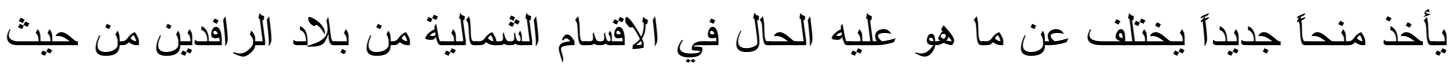

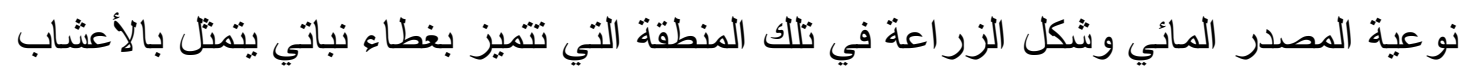

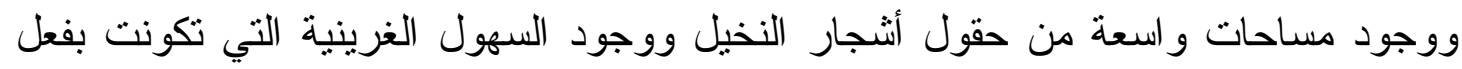

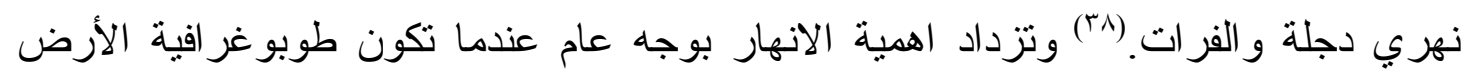

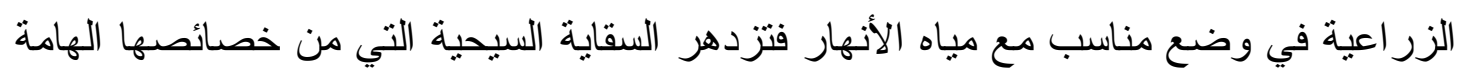

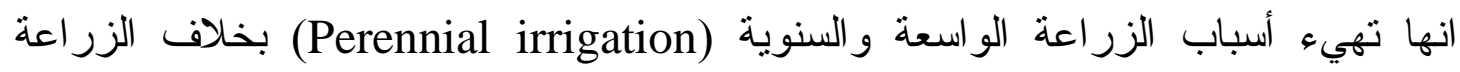

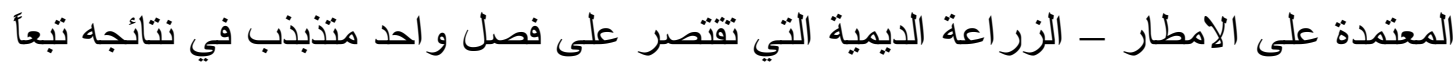
لكمية الأمطار الساقطة. (ª) وعليه فقد كان لنهري دجلة واعه والفرات الهميتهما القصوى في مجال اقامة مشاريع الري في هذا القسم من بلاد الر افدين و اهميتهما الزر اعية في المستوطنات و القرى الزر اعية في المنطقة والتي ندت تدريجيأ وتحولت الى مدن في القسم الجنوبي من العر فاق في

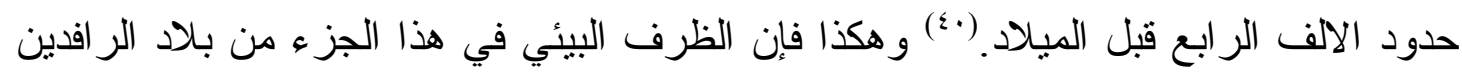
المتمثل بالمصدر المائي الأساس وهو الأنهار المعوض عن النقص في تذبذب مسنوى التساقط

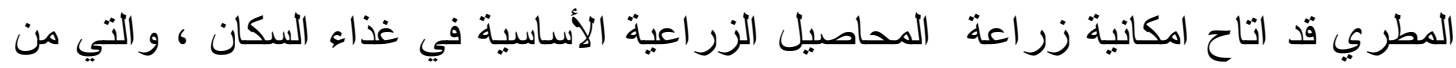
أبرزها الحبوب و المحاصيل الزيتية و الليفية وغيرها من الدحاصيل. كما انه قد حقق مسألة جوهرية في الحياة الزراعية هي الاستقرار ، اذ متل الاستقرار أبرز النتائج التي تحققت بفعل ونه

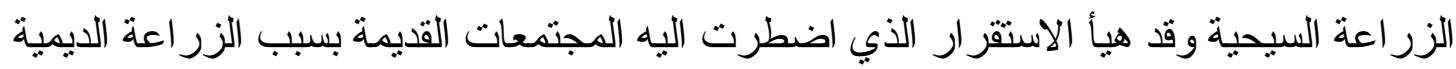
و السنوية ومتطلباتها الفرص أمام السكان الاو ائل لوضع أسس العلاقات الاقتصاد و والاجتماعية 
و عمل على تطويرها وحقق فرص التقدم المادي و الفكري (18) وهذا كله بفضل التأثير البيئي

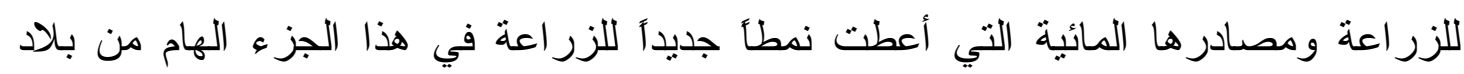

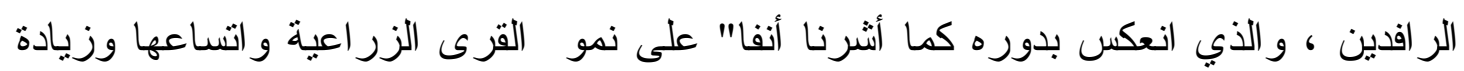

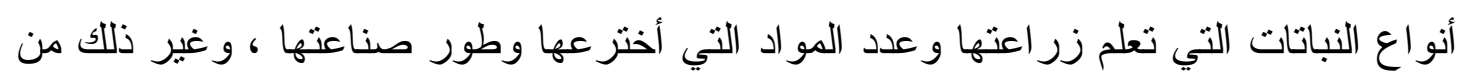
النطور ات. أنواتنات

ثانياً الصناعة :

تعد الصناعة أحد الأركان الثلاثة الرئيسة التي ترتكز عليها الحياة الاقتصاد ، وهي

وليدة تأثير ات فرضنها طبيعة البيئة وحاجة الانسان الضرورية لها لإيجاد احتجاجاته الحياتية.

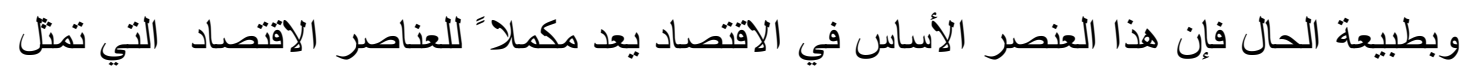

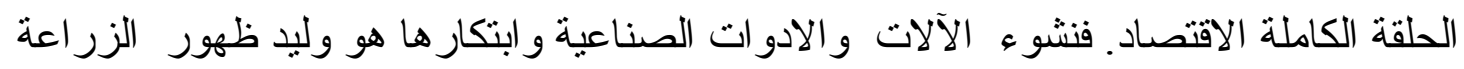
و ابتكار ها والتي لم تقم أو تستمر من دون وسيلة تعتمد عليها وتستتد اليها في فعالياتها ونشاطاتها

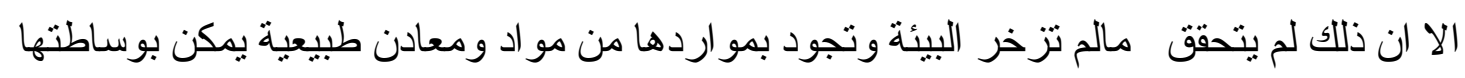

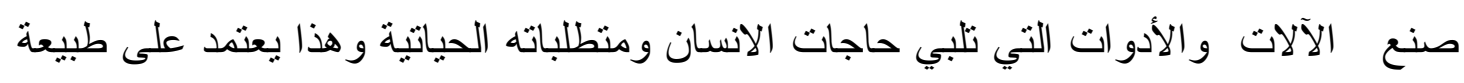

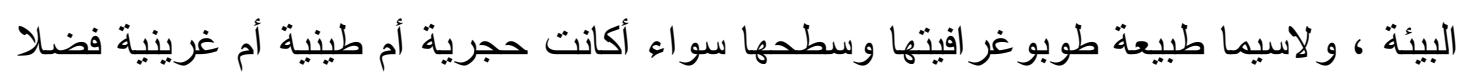

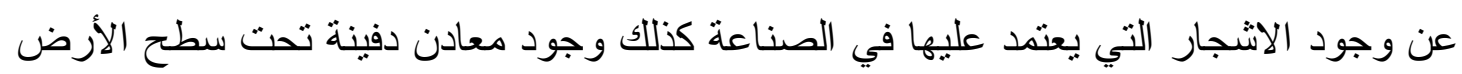

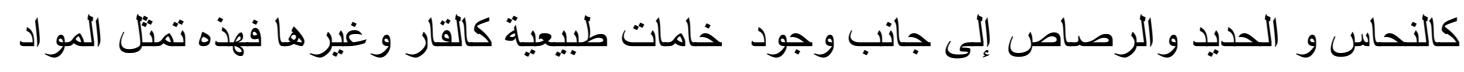
الأولية الاساسية في الصناعة وعناصر التصنيع التي تقوم عليها صناعة الآلات و والادوات.

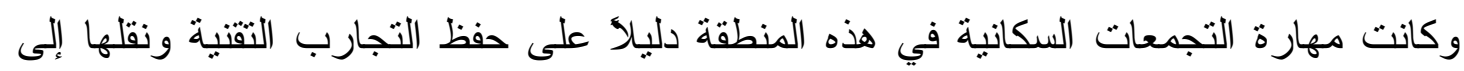

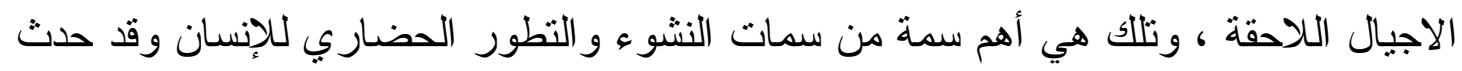

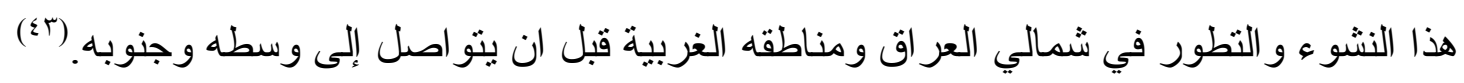

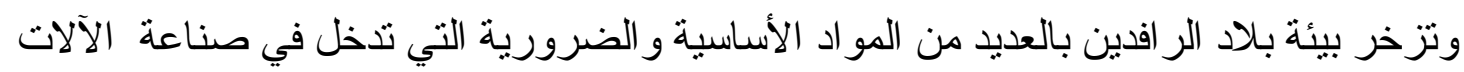

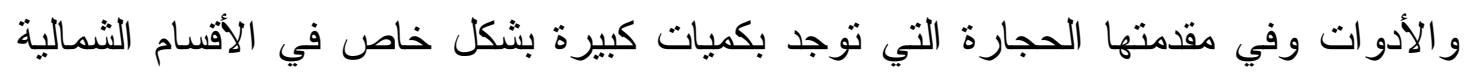

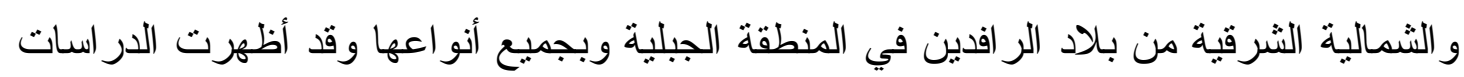
المختصة وجود أجزاء صخور قديمة جدأ تحت سطح المنطقة تسمى بالصخور النارية

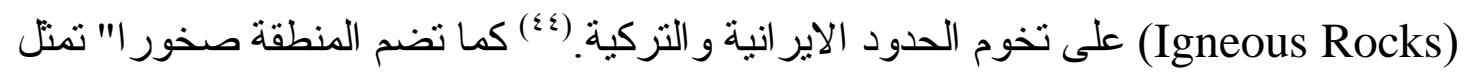

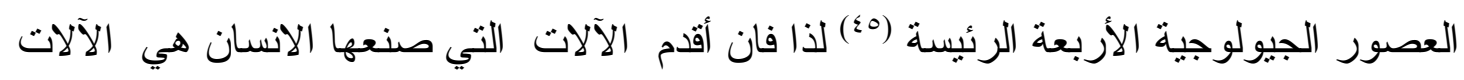

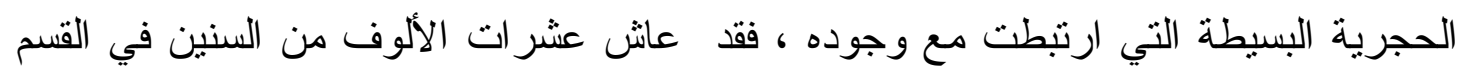

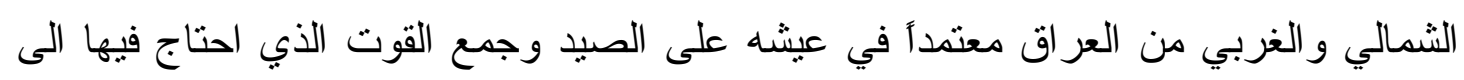


صنع أنو اع مختلفة من الآلات الحجرية لصيد الحيو انات وسلخها وتقطيعها كما أحتاج الى الآت أخرى لجمع الثمار و الحبوب وتقطيع الأشجار و استخدامها لفائدته. (آ؛) فالحجارة المتو افرة في بيئة شمال بلاد الر افدين وشمالها الثرقي قد مثلت المادة الأولى و الأقدم التي استخدمها الانسان في صنع ألاته و أدو اته الزر اعية و المنزلية فضلا عن الصبد و القنال وقد شكل استخدام مادة الحجر الأساس لمعظم الصناعات طيلة العصور الحجرية القديمة حتى بداية العصر الحجري المعدني ومنتصفه* فضلا عن جلبهم انو اعأ من الاحجار الصلدة الاخرى من المناطق و البلدان المجاورة ومنها الاوبسيدي و الفيروز و العقيق الأحمر و اللازود و الحجر الصابوني و الهيميتايت (حجر الدم) و البازلت.(`^) ومن المو اد الاولية التي زخرت بها بيئة بلاد الر افدين الطين و التربة الطينية أو الغرينية التي تميزت بها و لاسيما في منطقة السهل الرسوبي وقد شكل استخدامه مادة أساسية وهامة في الصناعات التي تمثلت بالصناعات الفخارية التي ظهرت في منتصف العصر الحجري الحديث إبان حقبة الألف الثامن و السابع قبل الميلاد و التي شكلت المادة الصناعية الثانية الى جانب الحجارة في صناعة الادو ات المنزلية الاساسية التي احتاجها الانسان في حياته اليومية وقد شكل استدامة في المنطقة السهلية من المنطقة الشمالية و الاجز اء الوسطى و الجنوبية من بلاد الر افدين وذلك لقلة وجود الاحجار في تلك المناطق مع تو افر المادة الطينية التي تتنتر مع امتداد نهري دجلة و الفرات ورو افدهما التي أمدت ثللك المناطق بالتربة الطينية و الغرينية. ويعد العر اقيون القدماء أول من صنع الفخار في العالم و استخدموه في حياتهم اليومية وقد كان الدافع ور اء صناعته الحياة الجديدة المستقرة وزيادة الانتاج.(^) وكان أول أهتدها لصناعة الفخار في الطور الثاني من العصر الحجري الحديث.(૧؛)وقد تمثل استخدام الفخار المصنوع من الطين في أربع مناطق رئيسة منلت أربع بيئات مختلفة قامت فيها الصناعات الفخارية المعتمدة على مادة الطين بشكل أساس هي جرمو (شمال العراق)، وسامر اء (وسط العراق)، وحلف (شمال غرب العراق حتى الحدود السورية التركية) و العبيد (جنوب العراق) وهي مناطق سهلية تتو افر فيها التزبة الطينية التي استخدم فيها الفخار في الصناعة التي شملت بشكل أساس الأواني والجرار و أقر اص المغازل و انواع من المدقات أو الفؤوس و المناحل و غيرها.(•) وتدخل المعادن التي تعد من المو اد الاولية الهامة في الصناعة من أهم *ما جادت به البيئة وما حوته من ثزوات طبيعية منلت تطور آ كبير آوبالغاً في مجال التصنيع الذي ادخل تطور ات كبيرة على حياة الانسان و مجتمعه ورقى به اثو اطاً كبيرة من التطور التقني و الصناعي الذي لم يشهده من قبل في مجال الصناعة و التصنيع وكان توصل العر اقيين القدماء و اهتدائهم الى التصنيع وبشكل خاص معدن النحاس واحداً من المعالم الصناعية و الفكرية الكبيرة التي قادت الى عدة نطورات لانتقال المجتمعات السكانية في العراق و المنطقة من مجتمع القرية الى مجتمع المدينة (اO). وقد شكلت 
تلاك المعرفة بالمعادن و استعمالها في صنع الآلات و الأدوات المتتوعة سمة من السمات المهمة

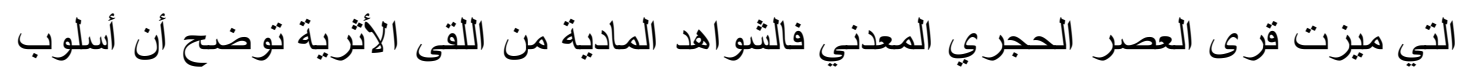

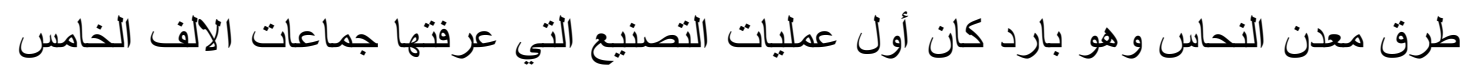
قبل الميلاد في شمال العر اق وكان تحويل النحاس على شكل رقائق قابلة لمرحلة تصنيع تالية على شكل أدوات بديلة لمعظم الأدوات الحجرية التي استمرت التجمعات السكانية باستخدامها قر ابة مليوني سنة قبل اهتدائهم لمعدن النحاس.(or) وقد شهدت المرحلة الثالثة من مرحلة القرى الثرى الزر اعية في العصر الحجري المعدني وبشكل خاص قرى وسط بلاد الر افدين وجنوبها اتجاهأ متز ايدا نحو الصناعات النحاسية متمثلة بأدوات منتوعة كرؤوس رماح وسكاكين وخناجر

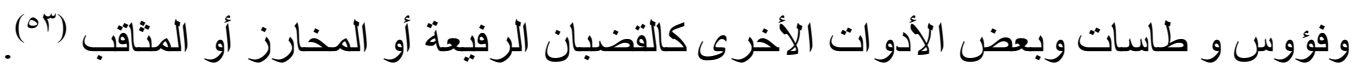

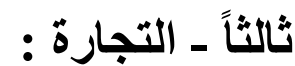

تعد التجارة إحدى المرتكز ات المهمة لاقتصاد ، وهي مكملة لعمليات الزر اعة و الصناعة

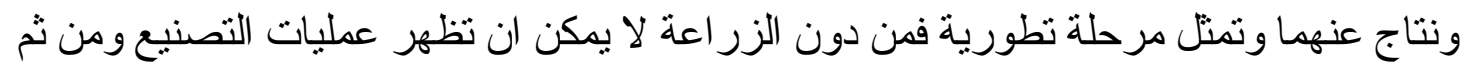

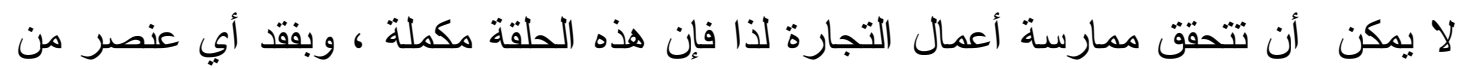

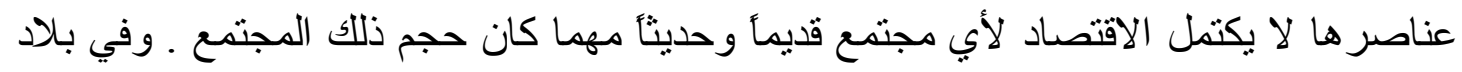

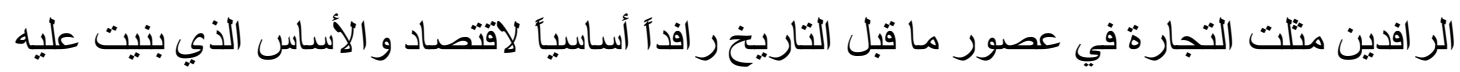
حركة الاقتصاد وتطوره في العصور اللاحقة.(ْ) وقد كان لتأثير البيئة ودور ها في هذا الدجال

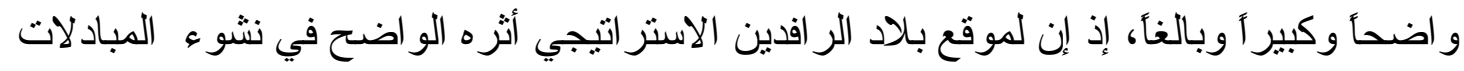

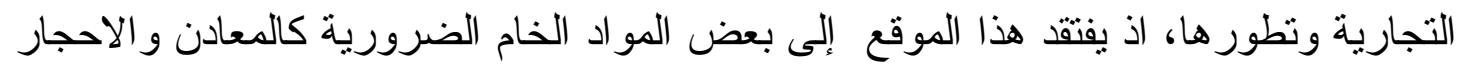

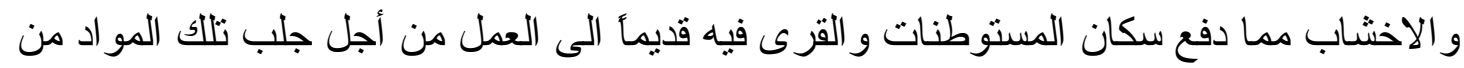

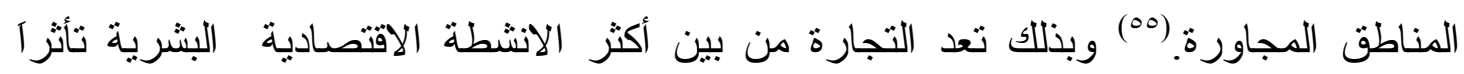
بظروف البيئة الطبيعية فقد استدعت متطلبات حياة الأفر اد عبر العصور نوفير الدو اد الخام نظر أنسأ

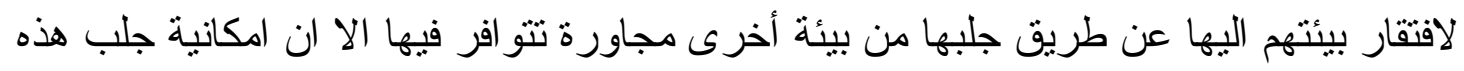

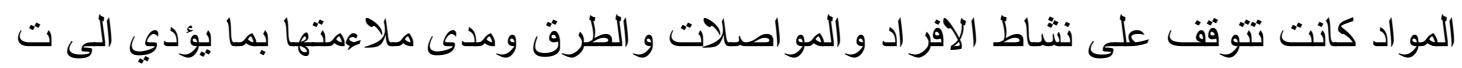
تأمين تلك المو اد. (07) وهكذا كانت بيئة بلاد الر افدين بخصائصها الطبيعية و امكانات سكانها

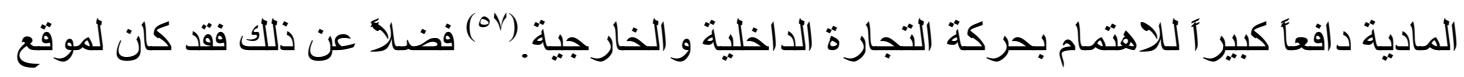
العر اق الجغر افي دوره الهام في قيام التجارة ونشاطها، اذ ان هذا الموقع المفتوح على مختلف

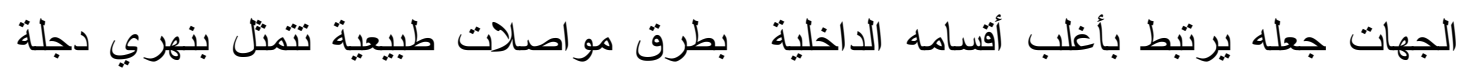

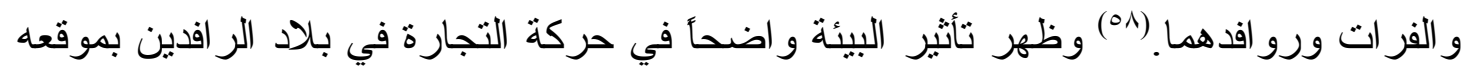


الجغر افي الذي أثرنا البه و الى طبيعة طوبو غر افية وتضاريسه وطرق الاتصالات الخارجية التي تزبطه مع المناطق المجاورة له، اذ ارتبطت عبر طرق مو اصلات جيدة وصالحة بمناطق الخليج العربي وه) وبلاد الثام وسواحل البحر المتوسط.(·) اما المناطق الجبلية في الجهات الشمالية و الثمالية الشرقية من بلاد الر افدين فقد كانت تتم عبر مدراتها المتاجرة مع مناطق

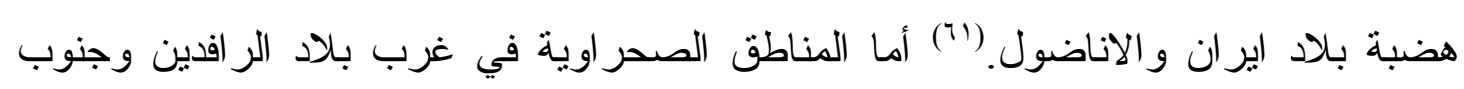
غربها فلم يكن هنالك عائق يمنع الوصول منها و اليها وخاصة في العصور التاريخية اللاحقة ، و لاسيما في حدود الالف الأول قبل الميلاد عندما عرف سكان بلاد الر افدين الجمل.(بآ) وهكذا يتبين الدور الحقيقي والبالغ للبيئة وتأثير ها في حركة التجارة في بلاد الر افدين عبر عاملين أساسين اولهما : انفتاح موقع بلاد الر افدين الجغر افي مع المناطق المجاورة له بشكل و اسع من ولن دون حو اجز وعو ائق طبيعية وربطة معها بطرق مو اصلات جيدة وسلسة نو عاً ما بكافة أجز ائه سواءً الثمالية أو الجنوبية ،الثرقية ،الغربية والتي مهدت بدورها لقيام صلات و علاقات اجتماعية ورو ابط ووشائج بين سكانه وسكان تلك المناطق بحكم التقارب الجغر افي بينهما ، وثانيهما ندرة أرض وبيئة بلاد الر افدين و افتقار ها للعديد من المو اد الخام الضرورية و الهامة ، إذ واذ قادت عمليات التتقيب الآتاري في مو اقع عصور ما قبل التاريخ في بلاد الر افدين إلى الكثف عن العديد من المو اد المصنوعة من مو اد لا تتو افر أساساً في بيئة بلاد الر افدين ومنها مثنا انو اع من الحجارة الاوبسيدية وبعض الأحجار الكريمة والأصداف البحرية و القو اقع و المعادن كالنحاس فكان ذلك الدليل الأكيد على قيام المبادلات التجارية بين المستوطنات و القرى العر اقية القديمة و المناطق التي تتو افر فيها هذه المو اد الأولية. (عان) 


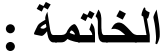

لعبت البيئة دور أ كبير أ وهامأ في الحياة الاقتصادية وكان لها أنز ا" بالغأ فيها وفرض عليها انماطأ ومسار ات محددة سارت نحو ها وخطت باتجاهها بعناصر ها الرئيسة الثلاث : الزر اعة، الصناعة، و التجارة ، وقد كان للبيئة في بلاد الر افدين الأثر الو اضح و الملموس حتمت عناصر ها

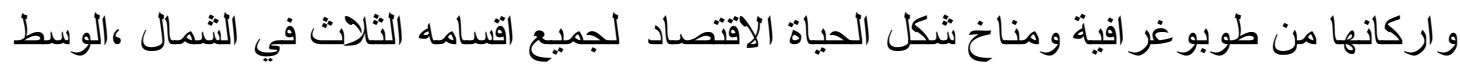
،الجنوب فثكل الحياة الاقتصاد في تلك الاقسام فرضتها طبيعة البيئة و عناصر ها المعروفة فيها و التي تباينت في كل منها حسب ظروفها البيئية الخاصة بها كما كثف التأثير البيئي في بلاد

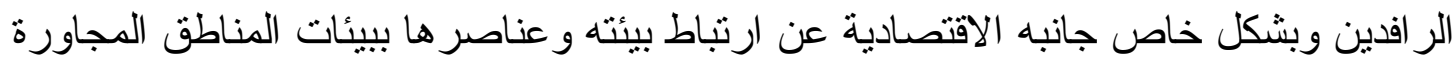
و المحادة له مبينتا" وحدة وتز ابط التأثير البيئي مع تلكك البيئات وهذا قد أدى بدوره الى رسم وتحديد شكل الحياة الاقتصاد بعناصرها الثلاث في بلاد الر افدين وتلك المناطق فكملت نلك المناطق الو احدة الأخرى وان تباينت نوعأ ما في بعض الثزوات الطبيعية الا انها بينت التأثير البيئي ذاته على الحياة الاقتصاد فيها، فعناصر الاقتصاد الثناث كان الثناثثير البيئي محددأ فيها عبر رسم صور ها و اثكالها من تنوع و ازدهار في المنطقة الجبلية من الأقسام الثنمالية ونو افر الفرائ مصادر مائية تقف كميات الامطار الغزيرة في مقدمتها مع درجات حرارة معتدلة الى تنذبذب و انخفاض منسوب كمية التساقط المطري و الاستعانة بالمصادر المائية المتمثلة بنهري دجلة و الفرات ورو افدهما كبديل لذلك واستخدم طرق الري الاصطناعي من خلالهما في الاقسام الوسطى و الجنوبية في السهل الرسوبي الى ندرة وانعدام كميات التساقط المطري و انعدام الحياة النباتية و اقتصار ها على نباتات صحر اوية في المنطقة الصحر اوية المنتلة بالهضبة الجنوبية

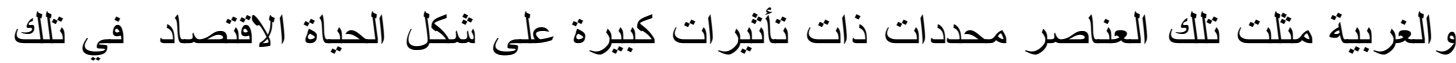
الاقسام كان له الاثر الكبير و المباشر في التوزيع السكاني فيها ودور ها الى جانب ما بذله السكان من جهود في توفير سبل العيش وديمومة الحياة التي يعتمد بقائها واستمر ارها على ما تجود به

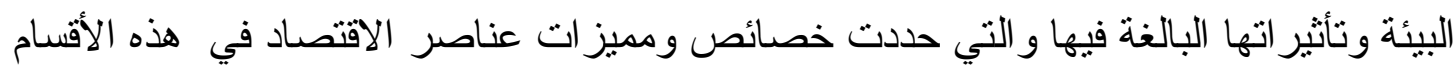
ورسم ملامح وصورة الحياة الاقتصاد فيهاوفق ذللك الأثر ومميز ات البيئة فيها. 


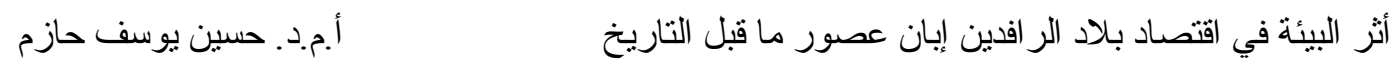

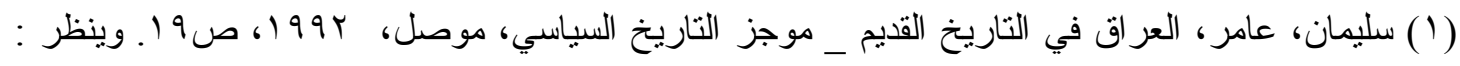

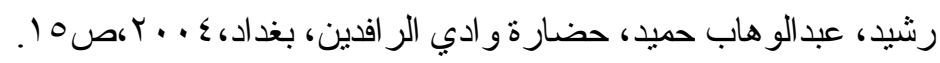

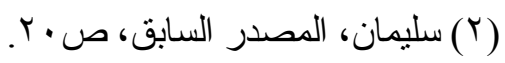

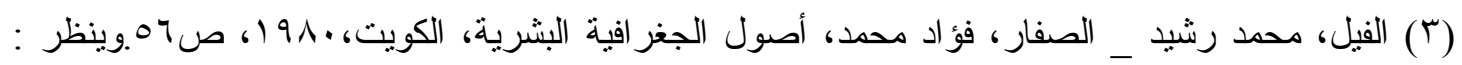

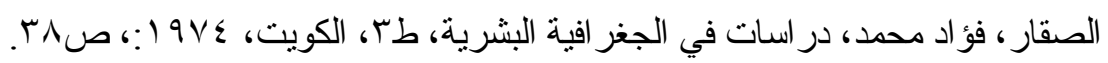

(4) Demieroop, M.V,A history of the ancient near east ca. 3000-323b.c, new york,2004,p.7.

وينظر : النجم، حسين يوسف حازم، اقتصاد القرى الزر اعية خلال العصريين الحجريين الحديث و المعدني في

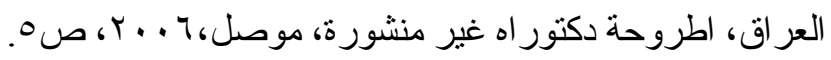

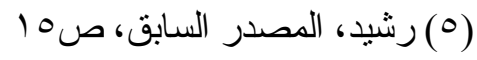

(؟) شريف، ابر اهيم، الموقع الجغر افي للعر اق و اثره في تاريخه العام حتى الفتح الاسلامي،ج ا، بغداد، د :ت،

See :Polbck. S. ‘Ancient Mesopotamia ‘cambridge ‘1999 ‘P.29.

الثيخ، عادل عبدالله، بدء الزر اعة واولى القرى في العراق، رسالة ماجسنير غير منشورة، بغداد 910 (V)

(^) الدباغ، نقي، "البيئة الطبيعية و الانسان" في : حضارة العر اق، جا بغداد، 910 ا، ص9 ب وينظر : النجم،

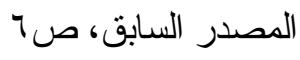

(9) Star,C.G.A history of the Ancient world ‘Oxford ‘1965 ‘P.29

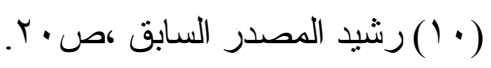

See: M.E.L Mesopotamia and Iran‘London‘1965، Mallowan P.16M.E, Early.

(11) Von Soden,w,the ancient ancient orient An introduction to the study of the near east, Translated by ; Donald ‘G.Schley, Michican, 1994, p.6.

(12) Mattewes‘R,The Early prehistory of Mesopotamia,5000.00 To 4.500 B.C. Brepols, 2000,p.5.

(13) Herbert,E. - Wright "Jr."" Climate and prehistoric Man In the Eastern Mediterranean "" ‘In : prehistoric Man In the eastern Medications In Iraqi Kurdistan ‘Chicago,1960,p.71.

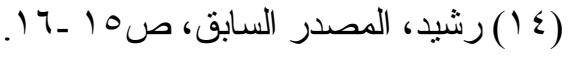

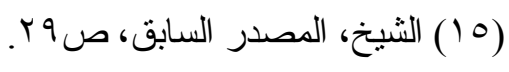

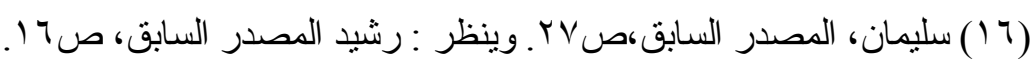

(17) Matthwes p.6, op.cit

وينظر : الحسني، فاضل باقر، "تطور مناخ العراق عبر الازمنة الجيولوجية والعصور التاريخية "". مجلة 


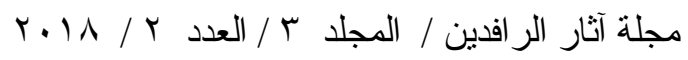

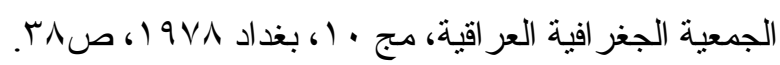

Matthwes, opcit, P.6. See:

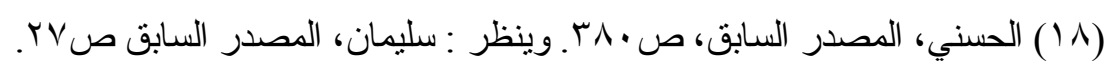

(19) pollock,op.cit.p.29.

$$
\begin{aligned}
& \text { وينظر : الحسني، المصدر السابق، ص. •^ץ. }
\end{aligned}
$$

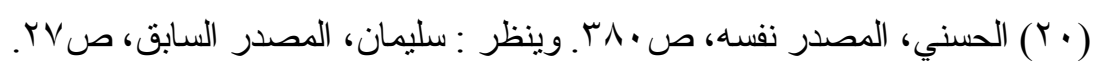

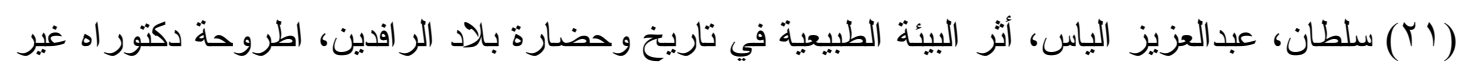

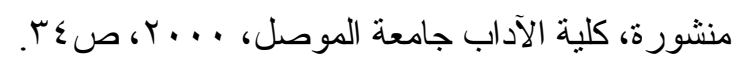

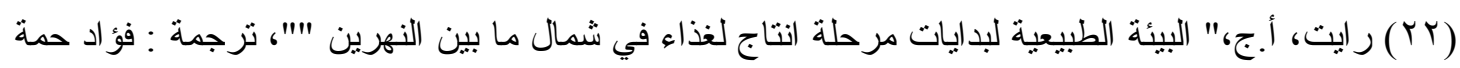

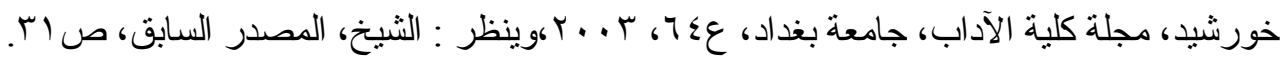

See:Season ‘J. M. ‘Civilizations of the Ancient Near East ‘New Yourk ،2000 ‘P.25.

(YTr) عبدالله، جميل نجيب،" الغابات الطبيعية في شمال العراق،"'" مجلة كلية الاداب، جامعة البصرة، عه،

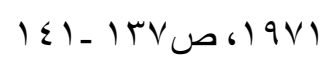

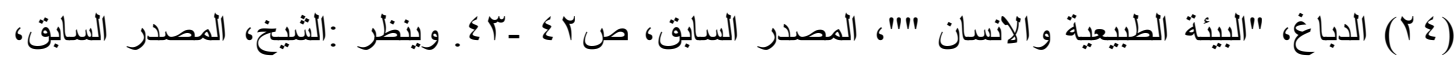

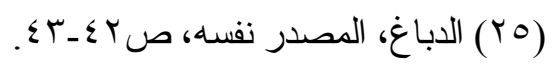$$
\text { عن تفاصيل هذا الموضوع، ينظر : }
$$

(26) Reed, C.A the in domestication " review of the Archaeological pre prehistoric near east", In; prehistoric investication in Iraqi Kurdistan,p. 119. Also see : chervat ‘p. Mesopotamia Before history ‘Loondon ‘2002 ‘pp : 2-4.

$$
\text { : عن (Yv) }
$$

Mathews op.cit,pp: 79-89. ،

Also see : perkins‘D ،" The Beginnings of Animal Domestication in the near east ،in : AJA (American Journal of of Archaeology ‘Princeton) vol. 77 ، 1973 ، PP: $279-280$.

(28) star ‘C.G. ،a history of the Ancient world ‘oxford ‘1965 ‘P. 17.

Also see : Janick ،J.‘Neolithic Revolution and the discovery of Agriculture ، purdue university 2002.

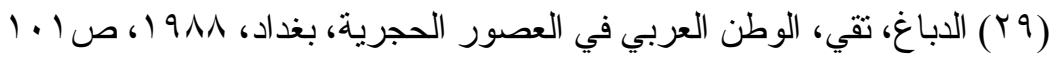

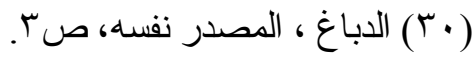

(32) Roaf. M. 'Cultural Atlas of Mesopotamia ‘the ancient near east ،Oxford ‘2003 P.

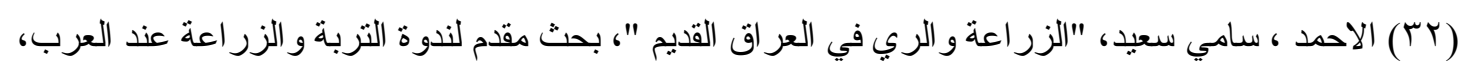

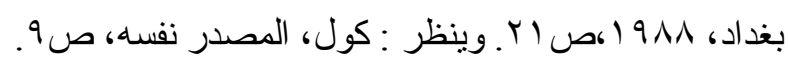

(33) Helback, H, "The paleothnobotany of the near east and Euroe", in : prehistory 
أ.م.د. حسين يوسف حازم

investication in iraqi kurdistan,op.cit,p.100.

Also see: Berger ‘R.-Protsch,R.," The domestication of plants and animals Europe and the near East ،in : or. ns (orintalia. Nora Series ‘Roma) ‘vol. 42 ،1973, p. 215

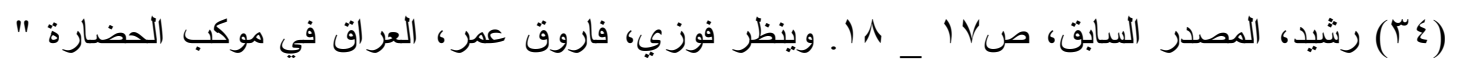

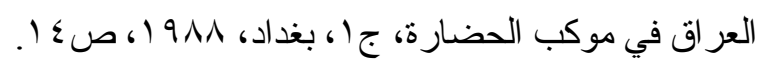

: نوع من الحنطة البرية كانت تتمو في المناطق الجافة ، وهي تسمية المائية تحمل سنابلها صنفين : Einkorn *

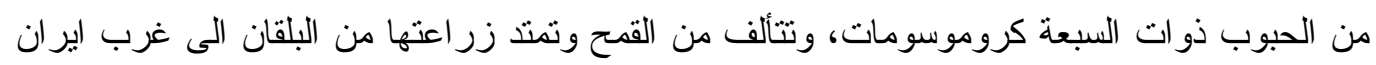

$$
\text { وجنوب شرق أسيا. }
$$

: نو عن الحنطة البدائية الاور اسية وهي تسمية المائية تحمل سنابلها أربعة صفوف من الحبوب ذات السبعة كروموسومات. وتوجد زر اعتها في شمال العراق وشرق تركيا و اير ان وجنوب سوريا وفلسطين

$$
\text { ينظر : رايت المصدر السابق، صـع ـ1 _ _ الاردن. }
$$

See also : mellart ‘J., earlist civilizations of the near east ،london ‘1965 ‘P.13.

* تتميز البيئات الطبيعية في منطقة الثرق الادنى بالتتوع و التغيير و التبدل ، وقد كان هناك مميز ات أساسية

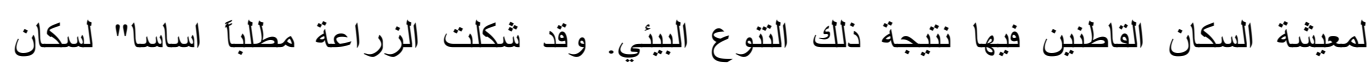

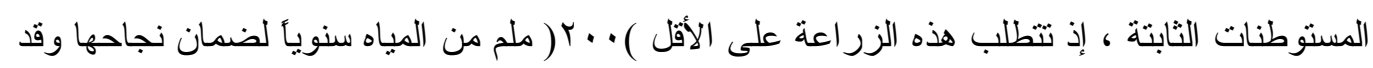

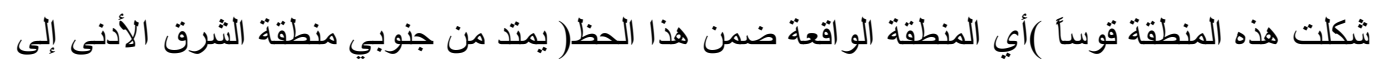
الخليج العربي .منها .

See : De Miroop،M.V. ‘A history of the Anicient Near east ca. $3000 \_323$ B.c. 'new york ،2004 ‘p.7.

(35) Pollock ‘op.cit ‘P.29.

(36) Kuhurt ،I. A. The ancient near east ‘London ‘2002 P.6.

Also see : Diakon off ‘I. M. Early antiquity ‘chicago ‘1991 ‘P.65.

وينظر ايضًأ: النجم، المصد السابق، ص 1'.

(37) pollock ‘op.cit, pp : $29 \_31$.

(38) Fernea ‘R. A. The central middle east 'new haven ‘1971.

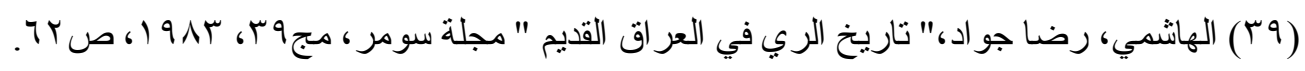

(40) Mallowan ‘M. Early Meso potamia and Iran ‘London ‘1965 ‘p.16.

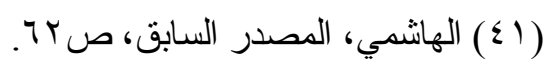

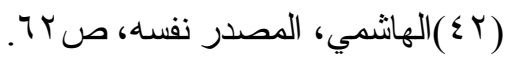

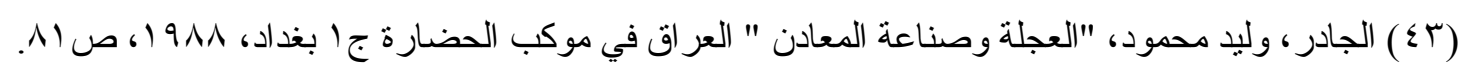

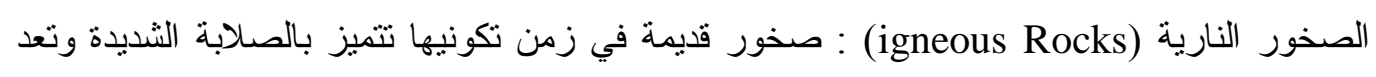

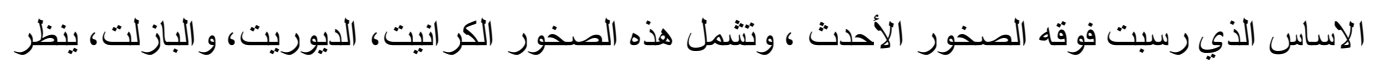




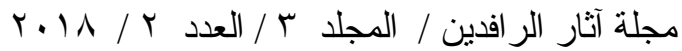

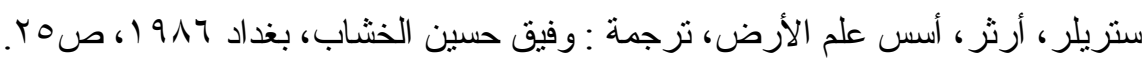

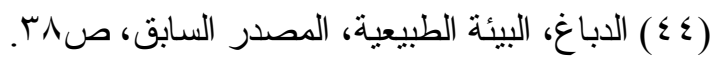

(0) العصور الجيولوجية الأربعة : وهي العصور التي مرت على سطح الآرض وشملت زمن الحياة القديمة وزمن الحياة الوسطى (Paleozoic age)

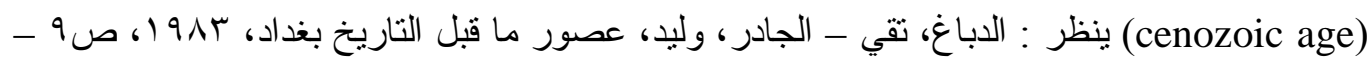

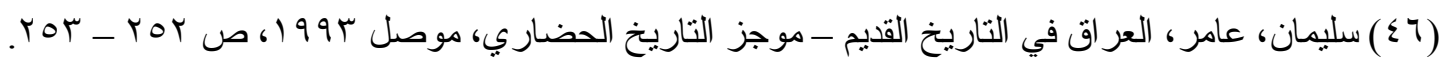

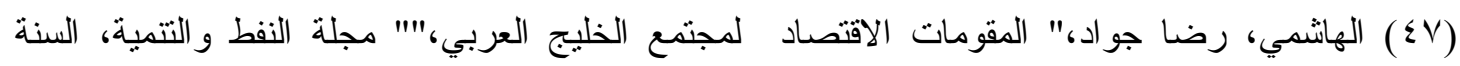

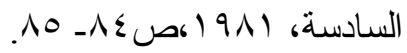

* اتبع السكان ومنذ عصور مبكرة في صنعهم الآلات الحجرية طرفتتن هما : طريقة صناعة الآت النواة وطريقة صناعة الآت الثظايا وقد تفر عت من الطريقتين طر ائق كثيرة أخرى. عن تلك الطر ائق ينظر :

Moorey ‘P.R.S.،"The archaeological Evidence for Metallurgy and Related technologies in Mesopotamia" ،550 - 2100 B.C. " in :Iraq ،Vol. XLIV ،Part 1 ، 1982, PP :59 - 66 .

Also see : Dakley ‘K. Man the tool Maker ‘London ‘ 1952 ‘P.25.

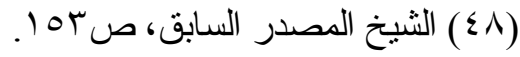

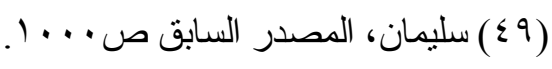

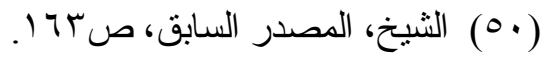

(51) Moorey ‘op.cit P.13

(52) ibid ‘P.13

وينظر ايضأ : الجادر، وليد محمود، "العجلة وصناعة المعادن " في :العراق في موكب

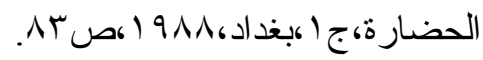

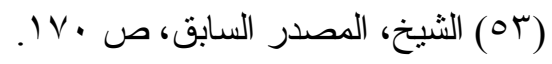

(54) Leemans‘W.F.،"the importance of trade،" In :Iraq،Vol.39،1977 ‘P.1.

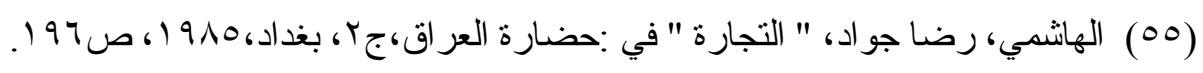

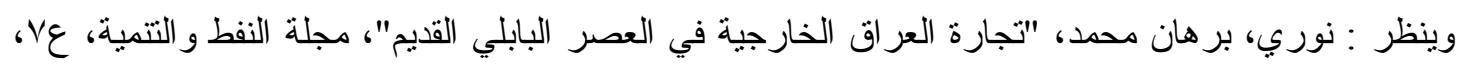
loV $19 \mathrm{Vr}$

(7ه) الهاثمي، رضا جو اد "هصلات العراق القديم التجارية بمناطق الخليج العربي " مجلة كلية الآداب ؛

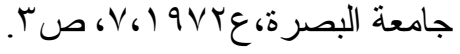

$$
\begin{aligned}
& \text { (OV) الهاشمي المصدر نفسه. }
\end{aligned}
$$

(01) الهاثمي، رضا جو اد، " دور نهر الفرات في الامتدادات الحضارية لبلاد و ادي الر افدين". مجلة بين

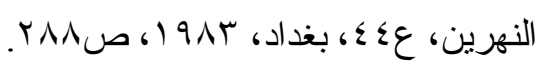

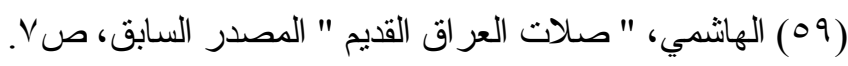




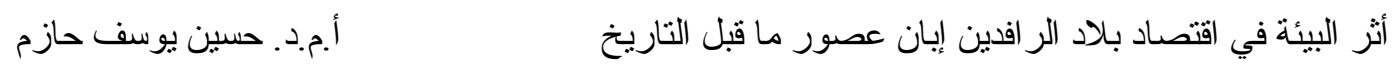

( • (7) غزالة، هديب حياوي، عبدالكريم، دور حضارة العراق القديمة في بلاد الثام، اطروحة دكتور اه غير

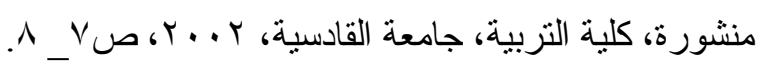

(61) Curtis ‘J. Ancient persia ‘London ،2000 ‘P.6.

Also see : Gerritderck sen ‘J. 'the old Assyrain copper trade in Anatolia ‘Holand ، 1996 ،PP.4_5.

( (T7) الهاثمي، " صلات العر اق القديم " المصدر السابق، ص^.

(63) charvat ‘op.cit ‘P.6. 




\section{Journal}

\section{AL- Rafedain Archaeology}

Accredited Scientific Journal

It Search's in Archaeology of Iraq and Ancient Near East

Published by College of Archaeology - University of Mosul

E_Mail:ali_aljuboori@yahoo.com 


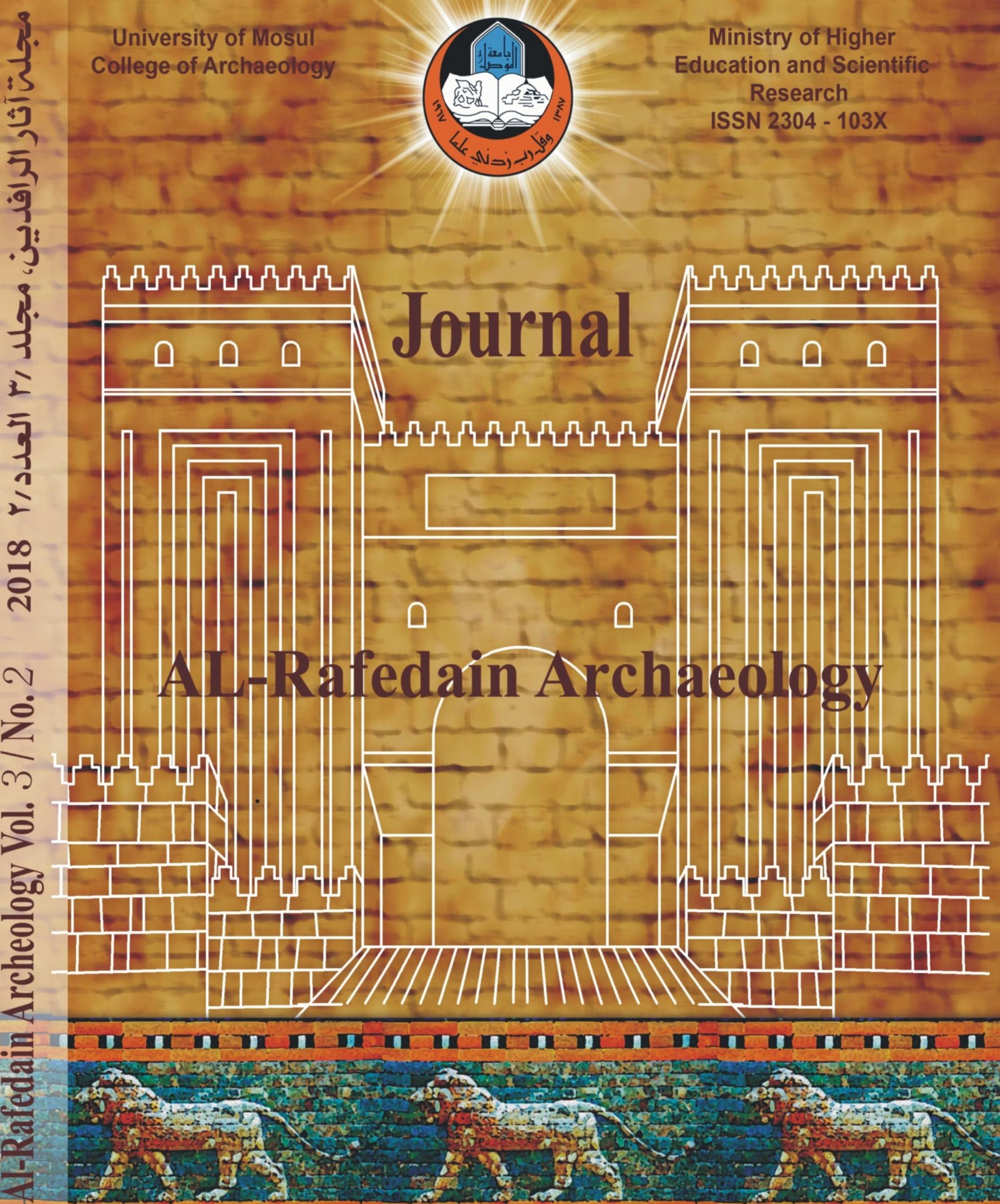

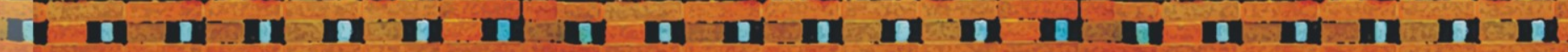

